\title{
Mobility and sex work: why, where, when? A typology of female-sex-worker mobility in Zimbabwe
}

Calum Davey $^{\mathrm{a}, *}$, Jeffrey Dirawo ${ }^{\mathrm{b}}$, Phillis Mushati ${ }^{\mathrm{b}}$, Sitholubuhle Magutshwa $^{\mathrm{b}}$, James R Hargreaves $^{\mathrm{a}}$, Frances M Cowan ${ }^{\mathrm{b}, \mathrm{c}}$

${ }^{a}$ London School of Hygiene and Tropical Medicine, 15 Tavistock Place, London, WC1H 9SH

${ }^{b}$ Centre for Sexual Health and HIV/AIDS Research, 9 Monmouth Rd, Avondale West, Harare ${ }^{c}$ Liverpool School of Tropical Medicine, Pembroke Place, Liverpool

\section{Acknowledgements}

CD was funded by a Strategic Skills pre-doctoral Fellowship from the Medical Research authors have conflicts of interest to declare. We are very grateful to all of the women who gave their time to be interviewed and for their assistance in recruiting their peers.

\footnotetext{
* Corresponding Author

Email address: calum.davey@lshtm.ac.uk (Calum Davey)
} 


\begin{abstract}
Sex worker mobility may have implications for health and access to care but has not been described in sub-Saharan Africa. We described sex-worker mobility in Zimbabwe and a mobility typology using data from 2,591 and 2,839 female sex workers in 14 sites from 2013 and 2016. We used latent class analysis to identify a typology of mobile sex workers. More women travelled for work in 2016 (59\%) than in 2013 (27\%), usually to find clients with more money (57\% of the journeys), spending a median of 21 (2013) and 24 (2016) days away. A five-class mixture model best fit the data, with $39 \%$ in an infrequent work-mobility class, $21 \%$ in a domestic-high-mobility class, $16 \%$ in an international-high-mobility class, $16 \%$ in an infrequent opportunistic-non-work-mobility class, and $7 \%$ who travel with clients. More-mobile classes were better educated; risk behaviours differed by class. Mobility is increasing among sex worker in Zimbabwe, multi-faceted, and not explained by other vulnerabilities.
\end{abstract}

Keywords: Sex work; migration; mobility; healthcare; HIV 
15

\section{Background}

Sex work takes different forms, but all involve the exchange of money or in-kind goods or services for sex (Raluca Buzdugan, Shiva S Halli, et al., 2009; Harcourt and Donovan, 2005). Sex workers often experience stigma (Scambler and Paoli, 2008), police harassment, arrest, client violence (Shannon and Csete, 2010), and worldwide are more likely to 20 be infected with HIV than women of the same age (Baral et al., 2012). Public-health programmes that meet the needs of sex workers are essential.

Sex work 'typologies' have been useful for understanding variation among sex workers to improve the design of health programmes (Jain and Saggurti, 2012). Various typologies have been used, for example: place of solicitation (Sinha, 1997), place of sex (Raluca

25 Buzdugan, Copas, et al., 2009), sex-work income (Hong et al., 2012), whether the primary purpose of the initial interaction is for exchanging sex (Harcourt and Donovan, 2005), and age (Delany-Moretlwe et al., 2015). Most of the research on sex work typologies has come from outside of sub-Saharan Africa.

Anecdotally, sex workers live highly-mobile lives, and there is evidence of high-levels of 30 mobility in the literature (Goldenberg et al., 2014; Reed et al., 2012). Mobility has many dimensions: people may move as individuals or with a partner or family; over various geographic distances and may cross social or civic boundaries; with different motivations for moving; to destinations that differ in various ways; more or less often (frequency); for shorter or longer stays (duration); where they can use healthcare; and seasonally or 35 periodically throughout the year or over a lifetime (Brown and Bell, 2004; Taylor et al., 2011). Mobile populations vary in the impact they have on the sending and receiving populations. A typology of sex-worker mobility that addresses the multiple-dimensional variation in mobility has not been developed.

There is limited quantitative literature on mobility of female sex workers in sub-Saharan 40 Africa. Brothel-based sex work is less common in sub-Saharan Africa than in Asia, and therefore the extent of and reasons for moving may be different. The little evidence available suggests that mobility can be high and varies by context: surveys of female sex 
workers conducted in 1997-98 in four sub-Saharan cities found that the average proportion of time spent in the city in the past year ranged from $69 \%$ in Cotonou $(\mathrm{N}=433)$ to $95 \%$ in 45 Ndola ( $\mathrm{N}=332$ ) (Morison et al., 2001). In the same years in Ghana, 17\% of female sex workers surveyed $(\mathrm{N}=1,013)$ had ever worked outside of the country (Asamoah-Adu et al., 2001). In Kenya, 403 women working on a highway spent $25 \%$ of 28 nights away from home 'base', and fewer than $20 \%$ of women spent all 28 days at the same place (Ferguson and Morris, 2007).

Although often associated with higher risks of HIV (see for example Reed et al. (2011), Reed et al. (2012), and Halli et al. (2010)) and other health concerns (for example, depression in Patel et al. (2016)), mobility can be thought of as a form of capital (Hall, 2005), broadly defined as a 'means to combine goals in space' (Hooimeijer and Van der Knaap, 1994). Short-term mobility that does not involve a semi-permanent change of ${ }_{55}$ address (although it usually involves at least one overnight stay (Smith, 1989)) can be thought of as a complement of migration (Bell and Ward, 2000), that can offer a lower-cost substitute for permanent migration in some circumstances (Pollard, 1996). Immobility, or stability (Hanson, 2005), may itself be a problem for women who need to find clients with money. Exploring the mobility of sex workers places emphasis more 'on work than 60 on sex' (Vanwesenbeeck, 2001), conceptualising sex work first in terms of labour, and second in terms of sexual risk: a focus that has been called for by sex-work organisations (RedTraSex, 2016).

We aimed to address the paucity of literature on mobility, especially in sub-Saharan Africa, by developing a typology of mobile sex workers. Using data from Zimbabwe collected 65 in fourteen sites in 2013 and 2016, we explored the extent of sex worker mobility across a number of dimensions. We hypothesised that types of mobility would be characterisable from the data, and that mobility would be associated with sociodemographic characteristics, for example that younger women, aged less than 25, and older women aged more than 40 would be less likely to move for work because of weaker social networks and less inclination 70 to travel, respectively. Viewed as a form of capital, we hypothesised that mobility would 
be associated with lower food insecurity, higher income per sex act, and more clients. With access to a larger client-base, we hypothesised that mobility would strengthen bargaining and be associated with higher reported condom-use with clients. We geolocated the names of places that sex workers reported visiting within the last year and described the the journeys, the sex workers' mobility, and the mobility from the places that the samples were drawn from. The results of this analysis may inform the design of services in the region, and mathematical models.

\section{Methods}

\section{Setting and data collection}

The data were collected as for the baseline and endline of the SAPPH-IRe trial, a cluster-randomised controlled trial of a complex intervention to reduce the proportion of the sex-worker population with an infectious level of HIV using a combination of: PrEP provision, immediate on-site ART initiation, and various forms of adherence support (Hargreaves et al., 2016). Details of the survey procedures have been published (Cowan

85 et al., 2017); in short: for each of fourteen sites across the country, community mapping was conducted and between six and eight female sex workers purposively sampled as representatives of sub-networks identified at each site. After consenting-to and completing a face-to-face interview, and providing a blood spot, each woman was given two coupons to invite her peers to participate in the survey. Women who presented with coupons 90 were asked for consent, interviewed, and asked for a blood spot, and given coupons two recruit two further female sex workers. This process of respondent-driven sampling (RDS, Heckathorn (1997)) continued until approximately 200 women were recruited in each site. Participants were compensated 5 USD for loss of earnings due to the interview, and a further 2 USD for each peer recruited. Women were eligible to participate if they had 95 exchanged money for sex in the last 30 days, were at least 18 years old, and had lived in the site for the past six months. 
Measures

Demographics and sex-work characteristics

The questionnaire included questions on: age, marital status (married, separated, divorced, widowed, never married), and highest education level completed (re-coded as 'no education', 'primary only', 'secondary or above'). The measures of food security differed between the two years, in 2013 women were coded as 'food insecure' if they reported any of: no to 'We can eat at least 2 meals a day', yes to 'sometimes we go to bed hungry', or yes to 'in the last week, have you had to go an entire day without eating because there was no food in your household?'; in 2016 women who reported yes to 'in the past four weeks, was there ever no food to eat of any kind in your house because of lack of resources to get food?' were coded as food insecure (drawn from Swindale and Bilinsky (2006)). Women were asked how old they were when they started sex work, how many clients they had in the last week (and whether this was more or less than average), and whether they consistently use condoms with clients (i.e. answered always to 'in the past month how often did you use condoms with your clients?' and no to 'think again about all the clients you had in the last month, have there been any times when you did not use condoms?').

The data were collected using RDS, therefore women had a non-random chance of being included in the survey. This could lead to bias, and the RDS-2 methodology inversely weights each individual according to their visibility in the network (Volz and Heckathorn, 2008). Women were asked how many other eligible women they knew, which was used to estimate their 'degree' in the network, i.e. the extent that each woman is connected to others. Often the number of eligible women each woman knows is used alone to weight the data (Malekinejad et al., 2008), however this can be noisy, clumped around commonly reported values (i.e. 10,50), and contain outliers. Therefore, we used a method developed by McLaughlin et al. (2015) to impute 'visibility' of each woman in the network from the number of eligible women that each woman knows, the time of the interview relative to the start of survey, and position in the chain of referrals. The scores were normalised to allow comparisons across sites. The purposively-selected women in each site were excluded 
calculated using the RDS-2 method, weighted by the inverse of the imputed visibility score.

\section{Mobility}

Women were asked if they had worked in sex work anywhere other than the interview site in the past 12 months, using the same question in both surveys. They were then asked to recall the places that they had been in reverse-chronological order. Women were asked to name up-to five places were they had worked in sex work and the duration of stay at each place. In 2016, women were also asked for the names and duration of stay in up-to five places where they did not work in sex work; they were also asked for the total number of places they visited, the reasons for visiting each place reported, and whether they used healthcare services while visiting. Duration was recorded as an ordered categorical variable (e.g. 'less than a week', '1-2 weeks', etc.), and was re-coded as a continuous variable in days using the mid-point of each category so that it could be summarised across visits for each woman (e.g. the median duration); in 2013 two periods were missed from the questionnaire (see Appendix 1). The typical amount charged per sex act, which was also recorded as categorical, was re-coded as a continuous variable in dollars (e.g. 'up to $\$ 2$ ' became $\$ 1, ' \$ 2-5$ ' as $\$ 3.5$, etc.). The data collection tools were piloted with sex-worker peer educators.

Places were recorded as reported by the participant with the name of the village, town or city, province, and country. These were written in the questionnaires by the interviewer, resulting in many spellings and misspellings. A full list of the places, as named, was generated for each site and researchers based in Harare identified the latitude and longitude coordinates of the places ('geocoded') by searching the Internet and using Google Maps (Google, 2018). When the name of a country was given without any town or city, the closest point on the Zimbabwean border from the site of interview was used.

Distances between places were estimated using the Google Maps API with the function mapdist in R package ggmap (Kahle and Wickham, 2013). The distances were 
for travel along a road, reported in kilometres and the hours it would have taken to travel by vehicle. Data on the province and country were downloaded from gadm.org 155 (http://www.gadm.org/download) and spatially joined with the data using the $s p$ package (Pebesma and Bivand, 2005). The code is available in Appendix 5.

\section{Statistical analysis}

Describing mobility. The journeys from the site of interview to the place visited were described in terms of the distance in kilometres, hours travelled, and the length of stay in days. The proportion of journeys between provinces, international, and between majority Shona-speaking eastern provinces and Ndbele-speaking western provinces was calculated. Places visited were categorised as 'town or city', 'growth point (official focal points for decentralisation of services into rural areas) or business centre', 'mine or farm', or 'other' other types of place included villages, resorts, and highways. Summaries were reported using the median and inter-quartile range.

To estimate the number of unique places visited per woman, the latitude and longitude coordinates were rounded to one decimal place, which corresponds to approximately $10 \mathrm{~km}^{2}$. Women were not asked if they returned to the site of interview between visits, therefore to summarise the distance travelled by each woman we calculated all of the possible journeys between the destinations and the site of interview (see Figure 1), calculated the median of the minimum and maximum distances that each woman could have travelled, and the median of 1000 medians from random draws of one journey per woman from all the possible journeys. We also presented the total distance when assuming that women returned to the site of interview between visits. Of the various features of mobility, we described: distance, frequency, duration, total time spent away, motivation (i.e. reason for moving), and whether or not reported using healthcare during the visit. We reported RDS-2 weighted medians and proportions.

We summarised the proportion of female sex workers who travelled and how long they spent away at the for each interview site. We estimated the median overall days spent away as a weighted average of the median time away for women who moved and the zero 
time away for those who did not move. We were unable to explore the impact on the receiving communities, for example how the number of women visiting a place compared to the local number of sex workers.

Sex work typologies. Prior to our analysis we hypothesised a typology of mobility for sex work. We hypothesised that mobile women would exhibit mobility behaviour consistent with three types:

(A) women who work in truck stops and travel with clients, with longer distances travelled, including internationally, not staying for long periods, and reporting 'to get more clients' or 'travel with clients' as the reasons.

(B) women who move seasonally or because of special events to specific places, with domestic travel to one or two places, staying for short periods, and reporting to 'find clients with more money' as the only reason.

(C) women who move frequently over short distances to find new markets, with multiple journeys over short distances, staying for moderate lengths of time, and giving reasons 'to find more clients' or 'to make more money by being new'.

After listing the most common sets of reasons for moving, and inspecting correlations between different features of mobility, we used a latent class analysis (LCA) approach to classifying types of women using a mixture model. LCA is a form of unsupervised machine learning (Masyn, 2013). We used the depmixS4 package, which allows for both binary and continuous manifest variables (Visser and Speekenbrink, 2010). We included the seven reasons that were reported for at least $5 \%$ of the journeys (the rest together as 'other'), and coded women by whether they ever gave each reason for any of the journeys reported. We included whether or not any travel was international, whether she ever travelled to a growth-point, or a mine, the median distance travelled, the median time away, and whether she lives in a town (as opposed to at a truck stop/colliery). We did not include the number of different places that women travelled to - this was very similar to the number of visits and there may have been under-reporting of repeat visits. The median-journey-time 
was log-transformed to account for skewed distributions; the median time away could not be transformed into a standard distribution and therefore was dichotomised into less than or more than two-weeks; the number of visits was modelled as Poisson (count); the other variables were modelled as binomial distributions (i.e. with a logit link function). To determine the number of classes, we ran the model for between two and 10 classes and plotted the Bayesian Information Criterion (BIC or Schwartz criterion) (Nylund et al., 2007) to identify a minimum using the 'scree-plot' method: better models were models at the minimum of the BIC curve and with the fewest possible classes. We ran each model 100 times with random starting values and plotted the $95 \%$ range to account for variation in the BIC between model runs, and to help determine whether we were finding local or global minima. We ran a series of diagnostics to evaluate the fit of models of classes around the minimum of the BIC plot and used Bootstrapping to compare the candidate models, described in Appendix 3.

To report the variability of mobility across sites, we plotted the density of the locations visited from each site in a $17 \times 15$ grid of 50x50km squares, organised by matched-pair for the trial and labelled with the 'type' of place (e.g. city, colliery, truck stop) and the proportion of the women who moved at each site who were members of each class identified 225 in the LCA.

Associations between mobility and socioeconomic and behavioural risk factors. We explored associations between mobility for sex work and sociodemographic characteristics by describing women in each of the identified types of mobility, including those who had not worked elsewhere. We used descriptive analysis, calculating the RDS-2 adjusted proportions and medians.

Ethics

[REDACTED TO ANONYMISE AUTHORS] 


\section{Results}

Demographics, sex work, mobility data

235 Demographic and sex-worker characteristics in both survey-rounds are shown in Table I. 2,591 women were recruited through RDS in 2013, and 2,839 in 2016, with similar age profiles. In both years, around a third had no education, primary education, and secondary education. Few women were married, the majority were divorced $(1,652 ; 63 \%$ in 2013 and 1,823; 64\% in 2016). Participants supported on average 1 child, and $45 \%$ and $42 \%$ were food insecure in 2013 and 2016, respectively. The median age that started sex work was 23 in 2013 and 24 in 2016. Women had median 5 clients in the past week, who were primarily solicited in bars, and $55 \%$ and $45 \%$ relied solely on selling sex for income in 2013 and 2016, respectively. In 2013, 65\% used condoms consistently with clients, 58\% in 2016. HIV prevalence was $60 \%$ in 2013 and $59 \%$ in 2016.

A higher proportion of female sex workers reported working elsewhere in the past 12 months in $2016(59 \%)$ than in $2013(27 \%)$. A similar proportion stayed elsewhere without working in 2016 (55\%), such that 2,294 women (81\%) reported any mobility in 2016. Of the mobile women, 681 (97\%) in 2013 and 2,293 (99.96\%) in 2016 reported the name of at least one place. The gazette of places worked or stayed contained 1,427 differently-spelled place-names, for 471 places. The coordinates were identified for 6,541 (99\%) of the places named; there were 929 places geo-coded in 2013, and 5,612 in 2016. In the 2013 survey, 27 women were missing place names, and 5 in 2016.

\section{Features of mobility}

The journeys are described in the upper panel of Table II. There were 929 journeys in 2013, and 3,364 in 2016 that included sex work and 2,248 that did not include sex work. The median distance was higher for non-work mobility, although women stayed for less time: median (inter-quartile range) of 4 (4-21) days as compared to 18 (4-21) when working. Most journeys were within Zimbabwe, only between $10 \%$ and $17 \%$ were to another country; even fewer (less than 10\%) travelled between linguistic areas within 
260

Zimbabwe. For places where women worked in sex work, 164 different places were visited a median (IQR) $2(1,6)$ times each in 2013, 270 places a median $3(1,11)$ times each in 2016, and 262 places were visited without working in 2016 , for $2(1,7)$ times each.

In 2016, women reported up to six reasons for moving for each journey reported. The most common reason to travel to places and work was to find clients with more money 265 (57\%), followed by to find more clients (39\%). For moves without work, the most common reason was to visit family $(72 \%)$. The results of listing the most common combinations of reasons given for travelling, and the correlations between the different features of mobility are reported in Appendix 2. In short, for travel that included sex work there were many combinations of reasons given for each journey, and the most common accounted for a small proportion of journeys. For moves without sex work, the most common combination was simply 'to visit family' and accounted for more than half of the total journeys. There were few strong correlations between features of mobility (Appendix Figure A2).

Only $12 \%$ and $8 \%$ of visits included the use of healthcare (Table II).

Women who made at least one journey are described in the middle panel of Table II.

275 The mean (IQR) visits per person to places where they worked increased from $1(1,1)$ to $2(1,3)$ between 2013 and 2016. In 2013 and 2016, women were away 21 and 24 days for work, and 14 without working in 2016.

The median number of days in the past 12 months spent in the interview location in 2013 was 359, and 342 in 2016. 17 (1\%) women reported spending more than the previous 12 months away working in 2016 (none in 2013), and 2 (0.1\%) when not working. The median (IQR) total distances in kilometres to places from the site of interview (and back again) was $356(180,662), 464(229,967)$, and $443(208,850)$ for 2013, 2016 with and without working, respectively. The median figures were similar for the mean of the random draws from the possible routes, but with narrower distributions.

285

Mobility described at the level of the sites of interview and the places visited is shown in the bottom panel of Table II. There was not considerable variation between sites, although the variability in the duration away was higher for moves that involved sex work 
than for non-sex-work mobility.

Sex work-mobility types

The LCA mixture model converged for all 100 runs for each of 2 to 10 classes; the BIC plot is shown in Appendix Figure A3.0. After five classes there was a bi-modal distribution of the BIC for each number of classes. For subsequent analyses we generated model fits drawn from the part of the BIC distribution with the lower mode. Comparisons between the models are described in Appendix 3. The five-class model was preferred; the likelihood-ratio test found that the five-class model was superior to the four-class (LRT $p$-value $=0.01$ ) but did not show an advantage of choosing more complex models (LRT $p$-value $=0.29)$. The probability profiles of the manifest variables are shown in Figure 2, with the probability of the class members exhibiting the binary variables is shown in grey-scale (black being 100\%), and the journey times and number of visits are described with the means in each class. We had hypothesised that there would be three types of mobile sex worker and our analysis identified five.

We expected to find a group of mobile sex workers who moved with clients but did not stay for long period, and we found that this group was small (class 1,7\%). The second expected group was those who move domestically moderately frequently to find clients, which was similar to the largest class, class 5 , with $39 \%$ of mobile women. The third was women who moved frequently over short distances staying for moderate lengths of time, closely resembling class 4 with $21 \%$ of the mobile women. These women were very likely to have visited a mine or farm for work. The two classes that we did not anticipate, therefore, were classes 2 and 3. Class 3 were women who reported working at places they had visited for reasons other than for work, and represented $16 \%$ of mobile women in the sample; class 2 were highly mobile and often travelled internationally over long distances and represented $16 \%$ of mobile female sex workers.

The five-class model was used to predict class membership, the demographics of the women in the classes are described in Table III, and by site in with density plots in 5 Figure 3. Few destinations from any one site accounted for more than $20 \%$ of the journeys 
(purple on the figures). There was a strong correspondence between site and class, with $100 \%$ of the mobile women in a single class in 10 of the 14 sites, although no class was only present in one site.

Women in the internationally mobile classes were more highly educated, more likely to

in Zimbabwe as increased dramatically between 2013 and 2016.

Our analysis faced a number of limitations. The first is that the inclusion criteria required that women had lived at the site for at least six months, potentially excluding some mobile women. The surveys took place over a short period and may have missed any women who were travelling during that time. It is likely that these issues led to an underestimate of the extent of mobility, and underestimated the proportions of the more mobile types of sex workers. The second is that the data were cross sectional, and we 
relied on recall over long periods to collect detailed data on mobility. Data on mobility from a cohort followed over time would improve the measures, however recruitment for cohort studies and follow-up of sex workers can be challenging (Ward and Day, 2006) which could reduce the representativeness of the study.

The analysis in this paper has a number of strengths. The places that women visited were geocoded directly, rather than, for example, using the centroids of provinces or other administrative areas. We took advantage of free and accessible software to calculate the distances in terms of travel by car along roads: in Zimbabwe, where intercity roads are scarce, the Euclidean distance may underestimate the journey distance. We investigated multiple dimensions of mobility, describing the features of mobility in detail at journey, women, and place levels before categorising participants using LCA. Distinguishing between moves for sex work and moves for other reasons resonates with the distinction between mobility for production, e.g. for work, and mobility for consumption, e.g. for leisure (Bell and Ward, 2000). However, many women engaged in sex work when they moved for other reasons, possibly reflecting the opportunistic and survival imperative behind much of sex work.

Measuring mobility has an inherent temporal problem: over what period are mobility events measured? Twelve months is relatively long, potentially affecting recall of visits which would underestimate mobility, while shorter periods might miss women who do not travel often. Richardson and Seethaler (2001) have suggested using just the one last trip, whenever it happened; however, had we used this we would not have been able to explore how mobility varied at the individual level. Our analysis was quantitative only, although we consulted with peer educators when developing the mobility tool for 2016. Qualitative data may have been informative for developing the typologies of sex worker by mobility. Finally, we did not have data on the unit of movement (i.e. whether women travelled with partners or children), or dates of travel that could have been used to explore seasonality and periodicity. We were not able to investigate the impact of the women visiting on the 370 sex worker populations (Brown and Bell, 2004). 
Non-sex workers in Zimbabwe are also increasingly mobile (Agency and International, 2016) (see Appendix 4 for a comparison between the de jure and de facto household members in the 2010 and 2015 DHS surveys). Around 10\% of people in the 2015 DHS survey were staying somewhere other than their usual residence on the day that the survey data was collected from their household. This is higher than the corresponding figure for sex workers in 2016: the median total time away in our survey of sex workers in 2016 was 28 and therefore we would expect to find $(28 / 365) \cdot 100 \%=7.7 \%$ women away from home if they were surveyed at home as for the DHS. However, since the RDS surveys were conducted over two weeks at each site, it is possible that mobile women would not be available to take part, as the DHS results emphasise. Women reported knowing a median of 9 others in 2016 who they could potentially recruit, however only $60 \%$ recruited two others for the survey in waves $0-4$; it is likely that many factors would contribute to this, including mobility.

Our analysis identified five different types of mobility based on multiple features. Previous descriptions of sex worker mobility have focused on frequency (Reed et al., 2012), reasons for moving (especially whether physically forced, or tricked, or with own agency (Agustín, 2005; Steen et al., 2015)), type of place visited (Halli et al., 2010), or crossing national borders (Richter et al., 2014). Our analysis shows that these features overlap when defining sex worker mobility. For example, $21 \%$ of the mobile women were domestically mobile and travelled about two-and-a-half times per year over short distances, $16 \%$ rarely travelled explicitly because of sex work but travelled longer distances and worked while visiting nonetheless, and just 7\% travelled with a client and stayed for less than two weeks.

Literature on mobility in low income settings has described 'circulatory' migration or mobility often as moves back and forth between two locations, or at least between places to an original 'home' (Chapman and Prothero, 1983; Zelinsky, 1971), however whether all mobile people have a specific location called 'home' has been questioned (Behr and Gober, 1982). In our analysis we relaxed the assumption that the women returned to one fixed place between visits, and although this did not have an enormous effect on the median 
distances covered, it did reduce long-distance outliers, which may be the journey patterns

that were the most unlikely (because women might prefer more efficient routes connecting the visited places). In future research on mobility among sex workers, women should be asked about how they travelled from one place to another and whether it included a return 'home', perhaps by completing a timeline of locations and time spent in each place.

We did not find that many women reported moving because of harassment or breakdown in relationships. Most women in Zimbabwe work independent of pimps or other intermediaries (Wilson et al., 1989). However, given the high rate of food insecurity and that most of the women relied on sex work as their only source of income, mobility should be interpreted within a conceptual model that acknowledges that personal agency is constrained and influenced by, among other things, extreme poverty (Hagen-Zanker, 2008). More research, including qualitative research, is needed to investigate the health and well being impacts, both negative and positive, of mobility and stability among sex workers.

Further research is needed to understand more about why women move within a structural framework. Although we did not find that typologies of sex work were associated with key indicators of behavioural risk, future work should explore the implications of mobility for access to healthcare, and for adherence to treatment regimens such as for antiretroviral therapy.

Word count. 5,318 


\section{References} Karnataka, India. International journal of epidemiology 39, 439-448.

Buzdugan, R., Halli, S.S., Cowan, F.M., 2009. The female sex work typology in India in the context of HIV/AIDS. Tropical Medicine \& International Health 14, 673-687.

Chapman, M., Prothero, R.M., 1983. Themes on circulation in the third world. 445

Agency, Z.N.S., International, I., 2016. Zimbabwe demographic and health survey 2015: Final report. Zimbabwe National Statistics Agency (ZIMSTAT); ICF International, Rockville, Maryland, USA.

Agustín, L.M., 2005. Migrants in the mistress's house: Other voices in the" trafficking" debate. Social Politics: International Studies in Gender, State and Society 12, 96-117.

Asamoah-Adu, C., Khonde, N., Avorkliah, M., Bekoe, V., Alary, M., Mondor, M., Frost, E., Deceuninck, G., Asamoah-Adu, A., Pépin, J., 2001. HIV infection among sex workers in Accra: need to target new recruits entering the trade. JAIDS Journal of Acquired Immune Deficiency Syndromes 28, 358-366.

Baral, S., Beyrer, C., Muessig, K., Poteat, T., Wirtz, A.L., Decker, M.R., Sherman, S.G., Kerrigan, D., 2012. Burden of HIV among female sex workers in low-income and middle-income countries: A systematic review and meta-analysis. The Lancet Infectious Diseases 12, 538-549.

Behr, M., Gober, P., 1982. When a residence is not a house: Examining residence-based migration definitions. The Professional Geographer 34, 178-184.

Bell, M., Ward, G., 2000. Comparing temporary mobility with permanent migration. Tourism Geographies 2, 87-107.

Brown, D., Bell, M., 2004. Measuring temporary mobility: Dimensions and issues. International Union for the Scientific Study of Population Twenty-Fifth Conference.

Buzdugan, R., Copas, A., Moses, S., Blanchard, J., Isac, S., Ramesh, B.M., Washington, R., Halli, S.S., Cowan, F.M., 2009. Devising a female sex work typology using data from

nternational Migration Review 597-632.

Cowan, F.M., Davey, C.B., Fearon, E., Mushati, P., Dirawo, J., Cambiano, V., 
Mavedzenge, S.N., Hanisch, D., Wong-Gruenwald, R., Chemhuru, M., others, 2017. The HIV care cascade among female sex workers in Zimbabwe: results of a population-based survey from the Sisters Antiretroviral therapy Programme for Prevention of HIV, an Integrated Response (SAPPH-IRe) trial. JAIDS Journal of Acquired Immune Deficiency Syndromes 74, 375-382.

Delany-Moretlwe, S., Cowan, F.M., Busza, J., Bolton-Moore, C., Kelley, K., Fairlie, L., 2015. Providing comprehensive health services for young key populations: Needs, barriers and gaps. Journal of the International AIDS Society 18.

Ferguson, A.G., Morris, C.N., 2007. Mapping transactional sex on the Northern Corridor highway in Kenya. Health Place 13, 504-19. https://doi.org/10.1016/j.healthplace. 2006.05 .009

Goldenberg, S.M., Chettiar, J., Nguyen, P., Dobrer, S., Montaner, J., Shannon, K., 2014. Complexities of short-term mobility for sex work and migration among sex workers:

Violence and sexual risks, barriers to care, and enhanced social and economic opportunities. Journal of Urban Health : Bulletin of the New York Academy of Medicine 91, 736-751. https://doi.org/10.1007/s11524-014-9888-1

Google, 2018. Https://www.google.co.uk/maps/.

Hagen-Zanker, J., 2008. Why do people migrate? A review of the theoretical literature. A Review of the Theoretical Literature (January 2008). Maastrcht Graduate School of Governance Working Paper.

Hall, C.M., 2005. Reconsidering the geography of tourism and contemporary mobility. Geographical Research 43, 125-139.

Halli, S.S., Buzdugan, R., Moses, S., Blanchard, J., Jain, A., Verma, R., Saggurti, N., 470 2010. High-risk sex among mobile female sex workers in the context of jatras (religious festivals) in karnataka, india. International Journal of STD \& AIDS 21, 746-751. https: //doi.org/10.1258/ijsa.2010.010192

Hanson, S., 2005. Perspectives on the geographic stability and mobility of people in 
cities. Proceedings of the National Academy of Sciences 102, 15301-15306. Infections 81, 201-206.

Hargreaves, J.R., Fearon, E., Davey, C., Phillips, A., Cambiano, V., Cowan, F.M., 2016. Statistical design and analysis plan for an impact evaluation of an HIV treatment and prevention intervention for female sex workers in Zimbabwe: a study protocol for a cluster randomised controlled trial. Trials 17, 6 .

Heckathorn, D., 1997. Respondent-driven sampling: A new approach to the study of hidden populations. Social Problems 44, 174-199.

Hong, Y., Zhang, C., Li, X., Fang, X., Lin, X., Zhou, Y., Liu, W., 2012. HIV testing behaviors among female sex workers in Southwest China. AIDS and Behavior 16, 44-52.

Hooimeijer, P., Van der Knaap, G., 1994. From flows of people to networks of behaviour. Nederlandse Geografische Studies 173, 178-187.

Jain, A.K., Saggurti, N., 2012. The extent and nature of fluidity in typologies of female sex work in southern India: implications for HIV prevention programs. Journal of HIV/AIDS \& social services 11, 169-191.

Kahle, D., Wickham, H., 2013. Ggmap: Spatial visualization with ggplot2. The R Journal 5, 144-161.

Malekinejad, M., Johnston, L.G., Kendall, C., Kerr, L.R.F.S., Rifkin, M.R., Rutherford, G.W., 2008. Using respondent-driven sampling methodology for HIV biological and behavioral surveillance in international settings: a systematic review. AIDS and Behavior $12,105-130$.

Masyn, K.E., 2013. Chapter 25 latent class analysis and finite mixture modeling. The Oxford handbook of quantitative methods 551.

McLaughlin, K.R., Handcock, M.S., Johnston, L.G., Japuki, X., Gexha-Bunjaku, D., Deva, E., others, 2015. Inference for the visibility distribution for respondent-driven sampling. American Statistical Association, Alexandria, VA.

Morison, L., Weiss, H.A., Buve, A., Carael, M., Abega, S.-C., Kaona, F., Kanhonou, 
L., Chege, J., Hayes, R.J., Heterogeneity of HIV Epidemics in African Cities, S.G. on, others, 2001. Commercial sex and the spread of HIV in four cities in sub-Saharan Africa. Aids 15, S61-S69.

Nylund, K.L., Asparouhov, T., Muthén, B.O., 2007. Deciding on the number of classes in latent class analysis and growth mixture modeling: A Monte Carlo simulation study. Structural equation modeling 14, 535-569.

Patel, S.K., Ganju, D., Prabhakar, P., Adhikary, R., 2016. Relationship between mobility, violence and major depression among female sex workers: A cross-sectional study in southern India. BMJ Open 6, e011439.

Pebesma, E.J., Bivand, R.S., 2005. Classes and methods for spatial data in R. R News $5,9-13$.

Pollard, H., 1996. Seasonal and permanent moves among the elderly, in: Newton, P., Bell, M. (Eds.), Population Shift: Mobility and Change in Australia. AGPS, pp. 378-91.

RedTraSex, 2016. RedTraSex statement at the high level.

Reed, E., Gupta, J., Biradavolu, M., Blankenship, K., 2012. Migration/mobility and risk factors for HIV among female sex workers in Andhra Pradesh, India: implications for HIV prevention. International journal of STD \& AIDS 23, e7-e13.

Reed, E., Gupta, J., Biradavolu, M., Devireddy, V., Blankenship, K.M., 2011. The role 520 of housing in determining HIV risk among female sex workers in Andhra Pradesh, India: considering women's life contexts. Social Science \& Medicinee \& medicine 72, 710-716.

Richardson, A., Seethaler, R., 2001. Estimating long distance travel behaviour from the most recent trip. TRB Transportation Research Circular E-C026-Personal Travel: The Long and Short of It.

${ }_{525}$ Richter, M., Chersich, M.F., Vearey, J., Sartorius, B., Temmerman, M., Luchters, S., 2014. Migration status, work conditions and health utilization of female sex workers in three South African cities. Journal of immigrant and minority health 16, 7-17.

Scambler, G., Paoli, F., 2008. Health work, female sex workers and HIV/AIDS: Global and local dimensions of stigma and deviance as barriers to effective interventions. Social 
530

science \& medicine $66,1848-1862$.

Shannon, K., Csete, J., 2010. Violence, condom negotiation, and HIV/STI risk among sex workers. JAMA 304, 573-574.

Sinha, M., 1997. A summary of the findings of the high risk behaviour study from 18 cities. National AIDS Control Organisation, Ministry of Health \& Family Welfare.

535 of the American Statistical Association 84, 430-436.

Steen, R., Jana, S., Reza-Paul, S., Richter, M., 2015. Trafficking, sex work, and HIV: efforts to resolve conflicts. The Lancet 385, 94-96.

Swindale, A., Bilinsky, P., 2006. Development of a universally applicable household food insecurity measurement tool: Process, current status, and outstanding issues. The Journal of nutrition 136, 1449S-1452S.

Taylor, B.S., Garduño, L.S., Reyes, E.V., Valiño, R., Rojas, R., Donastorg, Y., Brudney, K., Hirsch, J., 2011. HIV care for geographically mobile populations. Mount Sinai Journal of Medicine: A Journal of Translational and Personalized Medicine 78, 342-351.

545 review of research 1990-2000. Annual review of sex research 12, 242-289.

Visser, I., Speekenbrink, M., 2010. depmixS4: An R package for Hidden Markov Models. Journal of Statistical Software 36, 1-21.

Volz, E., Heckathorn, D.D., 2008. Probability based estimation theory for respondent driven sampling. Journal of Official Statistics 24, 79-97.

Ward, H., Day, S., 2006. What happens to women who sell sex? Report of a unique occupational cohort. Sexually Transmitted Infections 82, 413-417.

Wilson, D., Chiroro, P., Lavelle, S., Mutero, C., 1989. Sex worker, client sex behaviour and condom use in Harare, Zimbabwe. AIDS care 1, 269-280.

555

Zelinsky, W., 1971. The hypothesis of the mobility transition. Geographical review $219-249$. 
Mobility and sex work: why, where, when? A typology of female-sex-worker mobility in Zimbabwe

\section{Tables}

22 October, 2018

Table I: demographics and mobility data

Table II: mobility at the journey, woman, and site levels

Table III: sociodemographic and behavioural risks of different types of movers 


\begin{tabular}{|c|c|c|}
\hline \multicolumn{3}{|c|}{ Table I: demographics and mobility data } \\
\hline & Round 1, 2013 & Round 2, 2016 \\
\hline $\begin{array}{l}\mathrm{N} \\
\text { Age }\end{array}$ & 2,591 & 2,839 \\
\hline $\begin{array}{l}18-19 \\
20-24 \\
25-29 \\
30-39 \\
40+\end{array}$ & $\begin{array}{l}103 ; 4 \% \\
528 ; 20 \% \\
637 ; 24 \% \\
907 ; 36 \% \\
416 ; 17 \%\end{array}$ & $\begin{array}{c}50 ; 2 \% \\
448 ; 15 \% \\
602 ; 21 \% \\
1,136 ; 41 \% \\
603 ; 21 \%\end{array}$ \\
\hline $\begin{array}{l}\text { Education level } \\
\text { No education } \\
\text { Primary } \\
\text { Secondary }\end{array}$ & $\begin{array}{l}815 ; 32 \% \\
913 ; 35 \% \\
848 ; 33 \%\end{array}$ & $\begin{array}{l}881 ; 30 \% \\
993 ; 35 \% \\
964 ; 35 \%\end{array}$ \\
\hline $\begin{array}{l}\text { Marital status } \\
\text { Married } \\
\text { Divorced } \\
\text { Widowed } \\
\text { Never married }\end{array}$ & $\begin{array}{c}6 ; 0 \% \\
1,652 ; 63 \% \\
459 ; 18 \% \\
474 ; 18 \%\end{array}$ & $\begin{array}{c}41 ; 1 \% \\
1,823 ; 64 \% \\
552 ; 20 \% \\
422 ; 15 \%\end{array}$ \\
\hline $\begin{array}{l}\text { Child support (IQR) } \\
\text { Food insecure }\end{array}$ & $\begin{array}{c}1(1,2) \\
1,139 ; 45 \%\end{array}$ & $\begin{array}{c}1(1,2) \\
1,175 ; 42 \%\end{array}$ \\
\hline $\begin{array}{l}\text { Age started SW (IQR) } \\
\text { Clients in last week (IQR)† } \\
\text { Consistently uses condoms } \\
\text { SW only source of income } \\
\text { USD per short sex act (IQR) } \\
\text { Community considers as SW }\end{array}$ & $\begin{array}{l}23(20,28) \\
5(3,10) \\
1,512 ; 65 \% \\
1,423 ; 55 \% \\
4(4,8)\end{array}$ & $\begin{array}{l}24(20,29) \\
5(3,10) \\
1,524 ; 58 \% \\
1,292 ; 45 \% \\
4(4,4) \\
1,926 ; 69 \%\end{array}$ \\
\hline $\begin{array}{l}\text { Place of solicitation } \\
\text { Bar } \\
\text { Telephone } \\
\text { Street } \\
\text { Lodge } \\
\text { None of the above }\end{array}$ & $\begin{array}{c}1,862 ; 72 \% \\
162 ; 7 \% \\
442 ; 17 \% \\
16 ; 1 \% \\
106 ; 4 \%\end{array}$ & $\begin{array}{c}1,733 ; 64 \% \\
136 ; 5 \% \\
494 ; 19 \% \\
24 ; 1 \% \\
299 ; 11 \%\end{array}$ \\
\hline HIV & 1,$531 ; 60 \%$ & 1,$671 ; 59 \%$ \\
\hline Visibility (IQR)* & $6(5,9)$ & $6(5,8)$ \\
\hline $\begin{array}{l}\text { Mobility } \\
\text { Years living at site } \\
\text { Worked elsewhere past } 12 \text { months } \\
\text { Stayed elsewhere past } 12 \text { months } \\
\text { Any mobility in past } 12 \text { months } \\
\text { At least one place named } \\
\text { Total places named } \\
\text { with geocodes } \\
\text { type of place identified } \\
\text { with distances from site }\end{array}$ & $\begin{array}{c}8(3,21) \\
704 ; 27 \% \\
704 ; 27 \% \\
681 \\
929 \\
929 \\
929 \\
929\end{array}$ & $\begin{array}{c}9(3,23) \\
1,658 ; 59 \% \\
1,559 ; 55 \% \\
2,294 ; 81 \% \\
2,293 \\
5,654 \\
5,612 \\
5,611 \\
5,612\end{array}$ \\
\hline
\end{tabular}

Table 1: Data were missing for: age started sex work (2 women in 2016), consistent condom use ( 246 women in 2013, 211 in 2016), the price of a sex act (17 women in 2013, 12 in 2016), place of solicitation (153 women in 2016), length of time at the interview site (15 women in 2013), HIV status (16 women in 2013), and whether worked elsewhere (1 women in 2013, 6 in 2016). tWomen were asked whether this was more or less than average: in 2013 and 2016, 802/2575 and 920/2833 women said the last week was average, respectively. The majority in both years, 1,501 and 1,612 , said this was less than usual. * Visibility reported unweighted. 
Table II: mobility at the journey, woman, and site levels

\begin{tabular}{|c|c|c|c|}
\hline & \multirow[b]{2}{*}{ Round 1, 2013} & \multicolumn{2}{|c|}{ Round 2, 2016} \\
\hline & & Work & Non-work \\
\hline $\begin{array}{l}\text { N journeys } \\
\text { Median distance, km (IQR) } \\
\text { Median travel-time, hours (IQR) } \\
\text { Median stay, days (IQR) } \\
\text { Intra-province } \\
\text { Inter-province } \\
\text { International } \\
\text { To different linguistic area } \\
\text { To town or city } \\
\text { To growth point } \\
\text { To farm or mine } \\
\text { To other } \\
\text { Number of places } \\
\text { Median visits per place }\end{array}$ & $\begin{array}{c}929 \\
246(171-227) \\
3.4(2-3) \\
21(4-61) \\
401 ; 43 \% \\
372 ; 40 \% \\
156 ; 17 \% \\
90 ; 10 \% \\
551 ; 59 \% \\
127 ; 14 \% \\
143 ; 15 \% \\
108 ; 12 \% \\
164 \\
2(1,6)\end{array}$ & $\begin{array}{c}3,364 \\
246(150-238) \\
3.3(2-3) \\
18(4-21) \\
1,550 ; 46 \% \\
1,387 ; 41 \% \\
427 ; 13 \% \\
289 ; 9 \% \\
1,811 ; 54 \% \\
543 ; 16 \% \\
599 ; 18 \% \\
410 ; 12 \% \\
270 \\
3(1,11)\end{array}$ & $\begin{array}{c}2,248 \\
314(185-309) \\
4.3(3-4) \\
4(4-21) \\
813 ; 36 \% \\
1,206 ; 54 \% \\
229 ; 10 \% \\
165 ; 7 \% \\
1,302 ; 58 \% \\
338 ; 15 \% \\
289 ; 13 \% \\
319 ; 14 \% \\
262 \\
2(1,7)\end{array}$ \\
\hline $\begin{array}{l}\text { Reasons for travelling } \\
\text { Clients with more money } \\
\text { More clients } \\
\text { Earn more for being new } \\
\text { Travelled with client } \\
\text { Know FSW there } \\
\text { Familiar place } \\
\text { Anonymity } \\
\text { Holiday or festival } \\
\text { Police harassment } \\
\text { Avoid regular clients } \\
\text { Avoid other FSW } \\
\text { Avoid boyfriend or husband } \\
\text { Avoid family } \\
\text { Be with boyfriend or husband } \\
\text { Visit family } \\
\text { Visit children } \\
\text { Work other than sex work } \\
\text { To use medical services } \\
\text { Other } \\
\text { Used healthcare }\end{array}$ & & $\begin{array}{c}1,903 ; 57 \% \\
1,313 ; 39 \% \\
848 ; 25 \% \\
306 ; 9 \% \\
220 ; 7 \% \\
97 ; 3 \% \\
154 ; 5 \% \\
26 ; 1 \% \\
10 ; 0 \% \\
13 ; 0 \% \\
54 ; 2 \% \\
15 ; 0 \% \\
25 ; 1 \% \\
66 ; 2 \% \\
197 ; 6 \% \\
16 ; 0 \% \\
124 ; 4 \% \\
3 ; 0 \% \\
3 ; 0 \% \\
398 ; 12 \%\end{array}$ & $\begin{array}{c}14 ; 1 \% \\
6 ; 0 \% \\
71 ; 3 \% \\
1 ; 0 \% \\
2 ; 0 \% \\
5 ; 0 \% \\
1 ; 0 \% \\
4 ; 0 \% \\
30 ; 1 \% \\
1,614 ; 72 \% \\
113 ; 5 \% \\
229 ; 10 \% \\
26 ; 1 \% \\
26 ; 1 \% \\
185 ; 8 \%\end{array}$ \\
\hline $\begin{array}{l}\text { Individuals } \\
\text { N Individuals } \\
\text { Median visits (IQR) } \\
\text { Median different places (IQR) } \\
\text { Median total time away (IQR) } \\
\text { Visited town/city } \\
\text { Visited growth point } \\
\text { Visited mine/farm }\end{array}$ & $\begin{array}{c}681 \\
1(1,1) \\
1(1,1) \\
21(4,61) \\
448 ; 64 \% \\
116 ; 16 \% \\
123 ; 17 \%\end{array}$ & $\begin{array}{c}1,651 \\
2(1,3) \\
2(1,3) \\
24(7,64) \\
1,165 ; 70 \% \\
442 ; 27 \% \\
448 ; 27 \%\end{array}$ & $\begin{array}{c}1,548 \\
1(1,2) \\
1(1,2) \\
14(4,28) \\
1,003 ; 64 \% \\
319 ; 20 \% \\
261 ; 17 \%\end{array}$ \\
\hline $\begin{array}{l}\text { Median to-from dist. (IQR) } \\
\text { Median circuit dist (IQR) }\end{array}$ & $\begin{array}{l}356(180,662) \\
357(357,361)\end{array}$ & $\begin{array}{l}464(229,967) \\
464(460,468)\end{array}$ & $\begin{array}{l}443(208,850) \\
424(422,426)\end{array}$ \\
\hline $\begin{array}{l}\text { Sites } \\
\text { N Sites } \\
\text { Median journeys/site (IQR) } \\
\text { Median percentage who travel (IQR) } \\
\text { Median duration away (IQR) } \\
\text { Median distance (IQR) }\end{array}$ & $\begin{array}{c}14 \\
68(54,74) \\
28(22,31) \\
4(4,21) \\
123(101,160)\end{array}$ & $\begin{array}{c}14 \\
246(170,290) \\
59(46,65) \\
6(4,21) \\
136(90,178)\end{array}$ & $\begin{array}{c}14 \\
161(133,180) \\
55(47,60) \\
4(4,4) \\
182(108,223)\end{array}$ \\
\hline
\end{tabular}

Table 2: Mobility of sex workers described at the level of the journey, woman, and site of interview. Proportions and medians with Inter-quartile range are reported. There were 7 journeys without any reasons given. 


\begin{tabular}{|c|c|c|c|c|c|c|}
\hline \multicolumn{7}{|c|}{ Table II: sociodemographic and behavioural risks of different types of movers } \\
\hline & \multicolumn{5}{|c|}{ Mobility classes } & \multirow[b]{2}{*}{ Not-mobile } \\
\hline & Class 1 & Class 2 & Class 3 & Class 4 & Class 5 & \\
\hline N & 114 & 263 & 264 & 343 & 624 & 1175 \\
\hline $\begin{array}{l}18-19 \\
20-24 \\
25-29 \\
30-39 \\
40+\end{array}$ & $\begin{array}{c}2 ; 1 \% \\
18 ; 16 \% \\
33 ; 29 \% \\
46 ; 39 \% \\
15 ; 14 \%\end{array}$ & $\begin{array}{c}5 ; 2 \% \\
41 ; 14 \% \\
83 ; 32 \% \\
95 ; 36 \% \\
39 ; 16 \%\end{array}$ & $\begin{array}{c}4 ; 1 \% \\
52 ; 19 \% \\
56 ; 21 \% \\
120 ; 47 \% \\
32 ; 12 \%\end{array}$ & $\begin{array}{c}4 ; 1 \% \\
55 ; 15 \% \\
69 ; 21 \% \\
145 ; 43 \% \\
70 ; 20 \%\end{array}$ & $\begin{array}{r}10 ; 1 \% \\
103 ; 16 \% \\
140 ; 21 \% \\
254 ; 41 \% \\
117 ; 20 \%\end{array}$ & $\begin{array}{r}23 ; 2 \% \\
166 ; 14 \% \\
205 ; 17 \% \\
458 ; 40 \% \\
323 ; 27 \%\end{array}$ \\
\hline $\begin{array}{l}\text { Education level } \\
\text { No education } \\
\text { Primary } \\
\text { Secondary }\end{array}$ & $\begin{array}{l}36 ; 31 \% \\
47 ; 44 \% \\
31 ; 25 \%\end{array}$ & $\begin{array}{c}62 ; 23 \% \\
94 ; 35 \% \\
107 ; 42 \%\end{array}$ & $\begin{array}{l}96 ; 34 \% \\
86 ; 34 \% \\
82 ; 33 \%\end{array}$ & $\begin{array}{l}125 ; 35 \% \\
113 ; 32 \% \\
105 ; 32 \%\end{array}$ & $\begin{array}{l}142 ; 22 \% \\
238 ; 39 \% \\
243 ; 39 \%\end{array}$ & $\begin{array}{l}404 ; 33 \% \\
388 ; 34 \% \\
383 ; 33 \%\end{array}$ \\
\hline $\begin{array}{l}\text { Marital status } \\
\text { Married } \\
\text { Divorced } \\
\text { Widowed } \\
\text { Never married }\end{array}$ & $\begin{aligned} & 0 ; 0 \% \\
& 76 ; 67 \% \\
& 21 ; 19 \% \\
& 17 ; 14 \%\end{aligned}$ & $\begin{array}{c}2 ; 1 \% \\
195 ; 74 \% \\
31 ; 12 \% \\
35 ; 13 \%\end{array}$ & $\begin{array}{c}0 ; 0 \% \\
183 ; 69 \% \\
50 ; 20 \% \\
30 ; 11 \%\end{array}$ & $\begin{array}{c}6 ; 2 \% \\
212 ; 62 \% \\
71 ; 20 \% \\
54 ; 16 \%\end{array}$ & $\begin{array}{c}9 ; 1 \% \\
407 ; 65 \% \\
109 ; 18 \% \\
99 ; 16 \%\end{array}$ & $\begin{array}{r}23 ; 2 \% \\
710 ; 60 \% \\
259 ; 22 \% \\
183 ; 16 \%\end{array}$ \\
\hline $\begin{array}{l}\text { Child support (IQR) } \\
\text { Food insecure } \\
\text { Age started SW (IQR) } \\
\text { Clients in last week (IQR) } \\
\text { Consistently uses condoms } \\
\text { SW only source of income } \\
\text { USD per short sex act (IQR) } \\
\text { Community consider as SW }\end{array}$ & $\begin{array}{c}1(1,2) \\
40 ; 35 \% \\
24(20,29) \\
5(3,10) \\
48 ; 45 \% \\
63 ; 55 \% \\
4(4,4) \\
82 ; 73 \%\end{array}$ & $\begin{array}{c}1(1,2) \\
99 ; 38 \% \\
23(20,27) \\
6(3,12) \\
169 ; 67 \% \\
138 ; 51 \% \\
4(4,4) \\
163 ; 61 \%\end{array}$ & $\begin{array}{c}1(1,1) \\
143 ; 56 \% \\
24(20,28) \\
6(4,10) \\
125 ; 56 \% \\
170 ; 66 \% \\
4(4,4) \\
199 ; 77 \%\end{array}$ & $\begin{array}{c}1(1,2) \\
151 ; 46 \% \\
23(19,29) \\
5(3,10) \\
140 ; 46 \% \\
123 ; 36 \% \\
4(4,4) \\
245 ; 73 \%\end{array}$ & $\begin{array}{c}1(1,2) \\
245 ; 40 \% \\
23(19,28) \\
5(3,10) \\
345 ; 57 \% \\
256 ; 40 \% \\
4(4,8) \\
445 ; 72 \%\end{array}$ & $\begin{array}{c}1(1,2) \\
469 ; 40 \% \\
25(20,31) \\
4(2,8) \\
665 ; 62 \% \\
512 ; 44 \% \\
4(4,8) \\
749 ; 65 \%\end{array}$ \\
\hline $\begin{array}{l}\text { Place of solicitation } \\
\text { Bar } \\
\text { Telephone } \\
\text { Street } \\
\text { Lodge } \\
\text { None of the above }\end{array}$ & $\begin{array}{c}79 ; 73 \% \\
4 ; 4 \% \\
14 ; 14 \% \\
0 ; 0 \% \\
10 ; 10 \%\end{array}$ & $\begin{array}{c}157 ; 65 \% \\
17 ; 7 \% \\
45 ; 19 \% \\
1 ; 1 \% \\
19 ; 9 \%\end{array}$ & $\begin{array}{c}197 ; 77 \% \\
13 ; 5 \% \\
39 ; 14 \% \\
2 ; 1 \% \\
8 ; 3 \%\end{array}$ & $\begin{array}{c}187 ; 60 \% \\
9 ; 3 \% \\
81 ; 26 \% \\
5 ; 2 \% \\
34 ; 10 \%\end{array}$ & $\begin{array}{c}397 ; 67 \% \\
32 ; 6 \% \\
73 ; 13 \% \\
7 ; 1 \% \\
75 ; 13 \%\end{array}$ & $\begin{array}{c}684 ; 60 \% \\
57 ; 5 \% \\
230 ; 21 \% \\
9 ; 1 \% \\
151 ; 13 \%\end{array}$ \\
\hline $\begin{array}{l}\text { Years living at site (IQR) } \\
\text { HIV } \\
\text { Visibility } \\
\text { Stayed elsewhere }\end{array}$ & $\begin{array}{l}5(3,9) \\
79 ; 70 \% \\
7(6,9) \\
69 ; 61 \%\end{array}$ & $\begin{array}{c}7(3,19) \\
144 ; 54 \% \\
6(4,9) \\
158 ; 60 \%\end{array}$ & $\begin{array}{c}7(3,22) \\
175 ; 67 \% \\
7(6,9) \\
164 ; 62 \%\end{array}$ & $\begin{array}{c}9(4,24) \\
190 ; 53 \% \\
6(5,8) \\
190 ; 55 \%\end{array}$ & $\begin{array}{c}7(3,20) \\
341 ; 56 \% \\
6(4,8) \\
315 ; 50 \%\end{array}$ & $\begin{array}{c}11(4,26) \\
714 ; 61 \% \\
6(5,8) \\
636 ; 54 \%\end{array}$ \\
\hline
\end{tabular}

Table 3: There were 50 women excluded (missing data on at least one of the manifest variables), and 6 women missing data on working elsewhere. Class 1 travelled with clients. Class 2 travelled often over long distances and internationally. Class 3 worked when they travelled for other reasons. Class 4 travelled frequently over short distances for moderate periods. Class 5 moved domestically infrequently. 
Mobility and sex work: why, where, when? A typology of female-sex-worker mobility in Zimbabwe

\section{Figures}

22 October, 2018 
Figure 1: Circuits
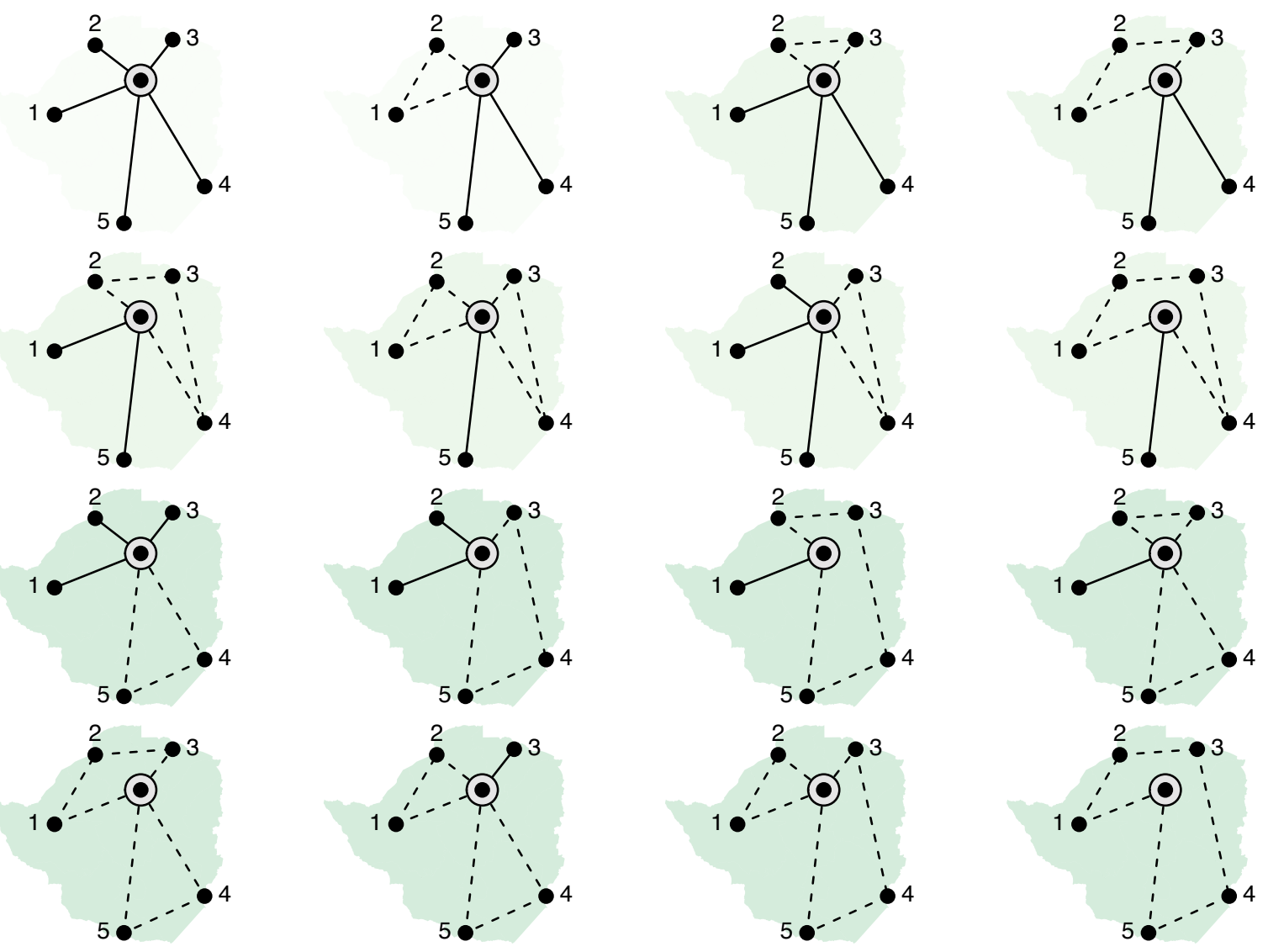

Figure 1 


\begin{tabular}{|c|c|c|c|c|c|}
\hline & $\begin{array}{c}\text { Class 1 } \\
(114,7 \%)\end{array}$ & $\begin{array}{c}\text { Class } 2 \\
(263,16 \%)\end{array}$ & $\begin{array}{c}\text { Class } 3 \\
(264,16 \%)\end{array}$ & $\begin{array}{c}\text { Class } 4 \\
(343,21 \%)\end{array}$ & $\begin{array}{c}\text { Class } 5 \\
(624,39 \%)\end{array}$ \\
\hline Visited growth point/business centre - & $19 \%$ & $16 \%$ & $10 \%$ & $24 \%$ & $39 \%$ \\
\hline Visited mine/farm - & $2 \%$ & $14 \%$ & $14 \%$ & $100 \%$ & $0 \%$ \\
\hline Clients with more money - & $12 \%$ & $86 \%$ & $16 \%$ & $86 \%$ & $81 \%$ \\
\hline More clients - & $1 \%$ & $68 \%$ & $6 \%$ & $62 \%$ & $64 \%$ \\
\hline Earn more for being new - & $2 \%$ & $47 \%$ & $10 \%$ & $43 \%$ & $40 \%$ \\
\hline Travelled with client - & $100 \%$ & $15 \%$ & $3 \%$ & $4 \%$ & $3 \%$ \\
\hline Know FSW there - & $5 \%$ & $16 \%$ & $19 \%$ & $10 \%$ & $9 \%$ \\
\hline Anonymity - & $0 \%$ & $14 \%$ & $3 \%$ & $7 \%$ & $8 \%$ \\
\hline Visit family - & $4 \%$ & $10 \%$ & $32 \%$ & $6 \%$ & $3 \%$ \\
\hline Other - & $9 \%$ & $32 \%$ & $49 \%$ & $14 \%$ & $12 \%$ \\
\hline Lives in a town - & $64 \%$ & $75 \%$ & $64 \%$ & $90 \%$ & $64 \%$ \\
\hline Median stay over two weeks - & $14 \%$ & $71 \%$ & $62 \%$ & $40 \%$ & $56 \%$ \\
\hline Travelled internationally - & $34 \%$ & $93 \%$ & $17 \%$ & $2 \%$ & $4 \%$ \\
\hline Median journey time (hours) - & 2.45 & 3.58 & 2.04 & 1.21 & 1.64 \\
\hline Number of visits in 12 months - & 1.81 & 2.51 & 1.51 & 2.44 & 1.74 \\
\hline
\end{tabular}

Figure 2 
Figure 3: density of destinations from sites
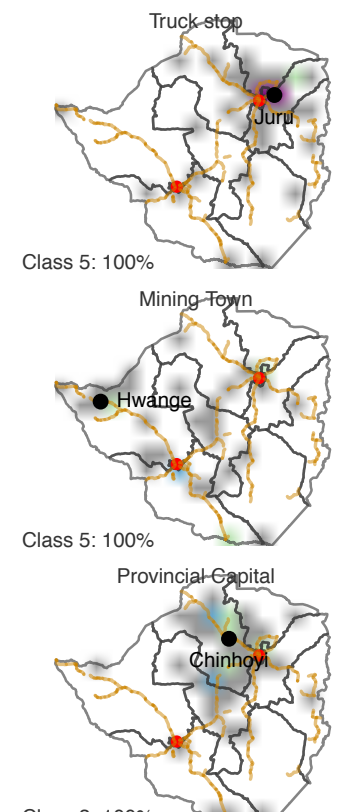

Class 3: $100 \%$

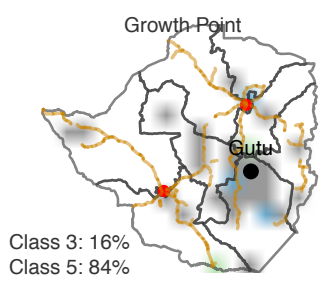

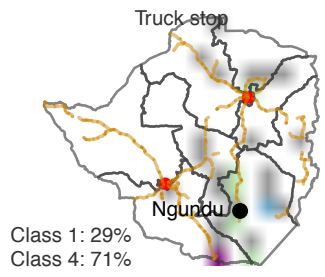
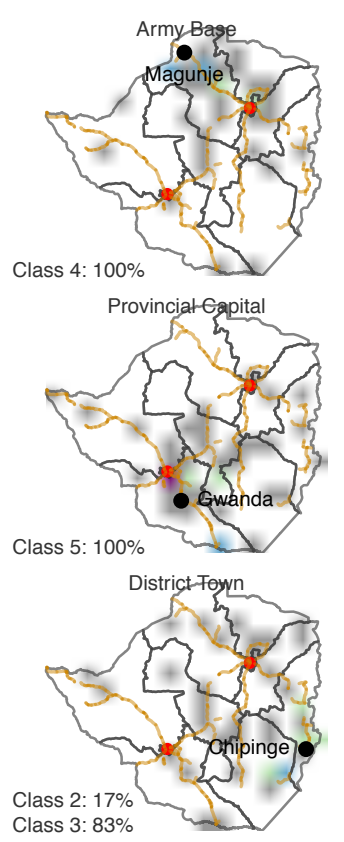

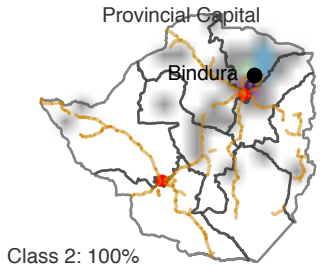

Class 2: $100 \%$
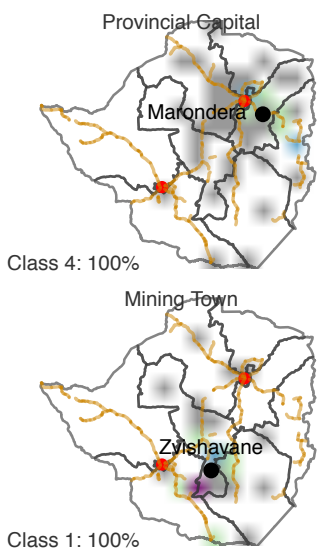

Class 1: $100 \%$
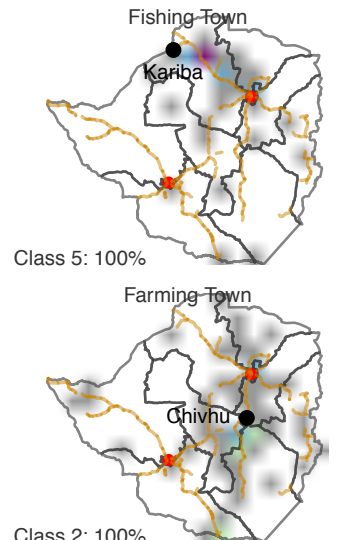

Class 2: $100 \%$

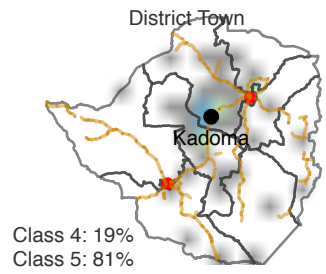
$0 \geq 5 \%$
- $6-10 \%$
- $11-20 \%$
- > $20 \%$

Figure 3 


\section{Captions}

\section{Figure 1}

10

Results of the five-class latent class model, with the classes ordered by size from left to

Illustration of the possible routes between places visited. Solid lines represent there-and-back journeys, dashed-lines represent one-way journeys. The first cell (top left) shows the there-and-back journey that is the only possible option with just one place reported. The second shows the second possible journey if two places are reported. Cells three and four show the two additional journeys possible with three places reported. Line two shows the four additional journeys possible with four reported places, and the bottom two rows show the eight additional journeys possible when five places were reported. Women always start from and return to the interview site and can choose to return or move to the next places from each place visited, therefore for $j$ places there are $j$-1 binary decisions, and hence $2^{j-1}$ journeys.

right. For the binary manifest variables, the posterior probabilities are shown with a continuous colour-scale from white (zero probability) to black (100\\% probability). The exponentiated intercepts of the median journey time and number of visits models are shown, i.e. the mean for the class.

\section{Figure 2}

Figure 3

The density of reported visits are shown for each interview site (labelled), with the type of place above each plot, using a $17 \times 15$ grid of $25550 \times 50 \mathrm{~km}$ squares. The proportion of the mobile women in each class from the six-class LCA model are shown on the bottom-left of each figure. 


\section{Appendix 1: recoding of duration-away variable}

\begin{tabular}{lcc}
\hline Duration in days & 2013 coding & 2016 coding \\
\hline 0 & - & Did not spend the night \\
3.5 & Less than a week & Less than a week \\
17.5 & - & $1-2$ weeks \\
21 & $2-4$ weeks & $2-4$ weeks \\
60.8 & $1-3$ months & $1-3$ months \\
152.1 & - & $4-6$ months \\
273.8 & $>6$ months & $>6$ months \\
\hline
\end{tabular}




\section{Appendix 2: configurations of reasons for moving}

Women could report multiple reasons for each journey reported. Therefore, we explored the

distribution of the reasons. We plotted the correlation at the journey-level between reasons, distance, and time spent away, separated by whether the visit included sex work. We listed the configurations of reasons by frequency, and reported the twenty most common configurations. The rows show the no / yes $(0 / 1)$ response for each reason for travelling, in the following order: Clients with more money*, More clients*, Earn more for being new*, Travelled with client*, Know FSW there*, Familiar place, Anonymity, Holiday or festival, Police harassment, Avoid regular clients, Avoid other FSW, Avoid boyfriend or husband, Avoid family, Be with boyfriend or husband, Visit family, Visit children, Work other than sex work, To use medical services, Other. The reasons marked with an asterisk $\left(^{*}\right)$ were not offered for moves that did not included working in sex work (e.g. for the second table below).

\begin{tabular}{lc}
\hline & cases \\
\hline $0-1-0-0-0-0-0-0-0-0-0-0-0-0-0-0-0-0-0$ & 656 \\
$1-1-0-0-0-0-0-0-0-0-0-0-0-0-0-0-0-0-0$ & 514 \\
$0-0-0-0-1-0-0-0-0-0-0-0-0-0-0-0-0-0-0$ & 267 \\
$1-1-1-0-0-0-0-0-0-0-0-0-0-0-0-0-0-0-0$ & 239 \\
$0-0-1-0-0-0-0-0-0-0-0-0-0-0-0-0-0-0-0$ & 213 \\
$1-0-0-0-0-0-0-0-0-0-0-0-0-0-0-0-0-0-0$ & 200 \\
$0-1-1-0-0-0-0-0-0-0-0-0-0-0-0-0-0-0-0$ & 149 \\
$0-0-0-0-0-0-0-0-0-0-0-0-0-0-1-0-0-0-0$ & 132 \\
$1-0-1-0-0-0-0-0-0-0-0-0-0-0-0-0-0-0-0$ & 98 \\
$0-0-0-1-0-0-0-0-0-0-0-0-0-0-0-0-0-0-0$ & 94 \\
$0-0-0-0-0-0-0-0-0-0-0-0-0-0-0-0-1-0-0$ & 71 \\
$0-0-0-0-0-0-0-0-0-0-0-0-0-1-0-0-0-0-0$ & 60 \\
$0-1-0-1-0-0-0-0-0-0-0-0-0-0-0-0-0-0-0$ & 41 \\
$0-0-0-0-0-0-0-0-0-0-0-0-0-0-0-0-0-0-1$ & 35 \\
$1-1-0-0-0-0-1-0-0-0-0-0-0-0-0-0-0-0-0$ & 33 \\
$0-0-0-0-0-0-0-0-0-0-1-0-0-0-0-0-0-0-0$ & 31 \\
$0-0-0-0-0-0-1-0-0-0-0-0-0-0-0-0-0-0-0$ & 29 \\
$0-0-0-0-0-1-0-0-0-0-0-0-0-0-0-0-0-0-0$ & 23 \\
$1-1-0-1-0-0-0-0-0-0-0-0-0-0-0-0-0-0-0$ & 20 \\
$0-1-0-0-0-0-1-0-0-0-0-0-0-0-0-0-0-0-0$ & 18 \\
\hline Remaining cases & \\
Remaining reasons & 441 \\
Total & 3364 \\
\hline
\end{tabular}

For the 3,364 moves that included sex work, the most common combination accounted for 656 of the journeys, and the second 514, leaving 2,194 journeys with other combinations of reasons. In contrast, for moves that did not include sex work, the most common combination of reasons constituted more than half of the total journeys $(1,533 / 2,248 ; 68 \%)$. 


\begin{tabular}{lc}
\hline & cases \\
\hline $0-0-0-0-0-0-0-0-0-1-0-0-0-0$ & 1533 \\
$0-0-0-0-0-0-0-0-0-0-0-1-0-0$ & 222 \\
$0-0-0-0-0-0-0-0-0-0-0-0-0-1$ & 218 \\
$0-0-0-0-0-0-0-0-0-0-1-0-0-0$ & 71 \\
$0-0-1-0-0-0-0-0-0-0-0-0-0-0$ & 61 \\
$0-0-0-0-0-0-0-0-0-1-1-0-0-0$ & 37 \\
$0-0-0-0-0-0-0-0-1-0-0-0-0-0$ & 27 \\
$0-0-0-0-0-0-0-0-0-0-0-0-1-0$ & 20 \\
$0-0-0-0-0-0-0-0-0-1-0-0-0-1$ & 12 \\
$0-0-1-0-0-0-0-0-0-1-0-0-0-0$ & 7 \\
$1-0-0-0-0-0-0-0-0-0-0-0-0-0$ & 7 \\
$0-0-0-0-0-1-0-0-0-0-0-0-0-0$ & 5 \\
$0-0-0-0-0-0-0-0-0-1-0-0-1-0$ & 2 \\
$0-0-0-0-0-0-0-0-1-1-0-0-0-0$ & 2 \\
$0-0-0-0-0-0-0-1-0-0-0-0-0-0$ & 2 \\
$0-0-0-0-1-0-0-0-0-0-0-0-0-0$ & 2 \\
$0-1-0-0-0-0-0-0-0-0-0-0-0-0$ & 2 \\
$0-1-0-0-0-0-0-0-0-1-0-0-0-0$ & 2 \\
$1-0-0-0-0-0-0-0-0-1-0-0-0-0$ & 2 \\
$0-0-0-0-0-0-0-0-0-0-1-0-1-0$ & 1 \\
\hline Remaining cases & \\
Remaining reasons & 13 \\
Total & 2248 \\
\hline
\end{tabular}


Fig. A2: correlations between reasons for moving

24

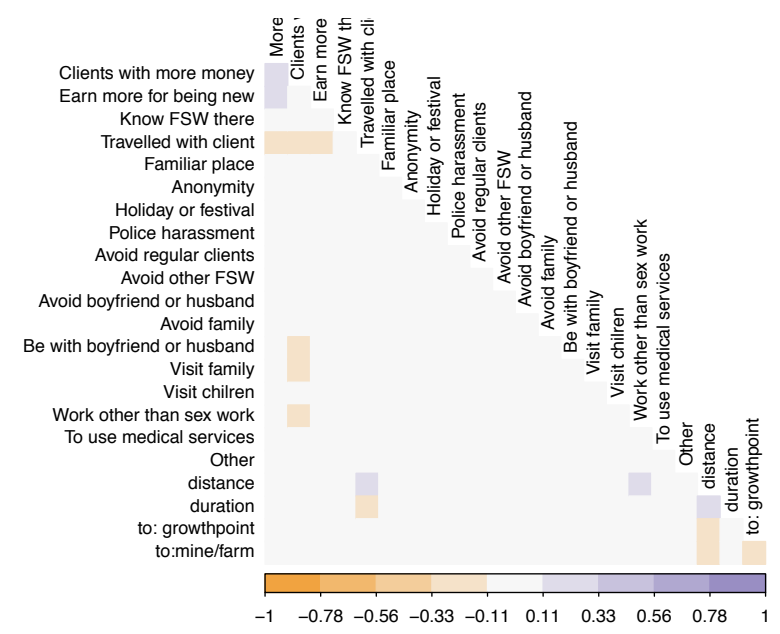

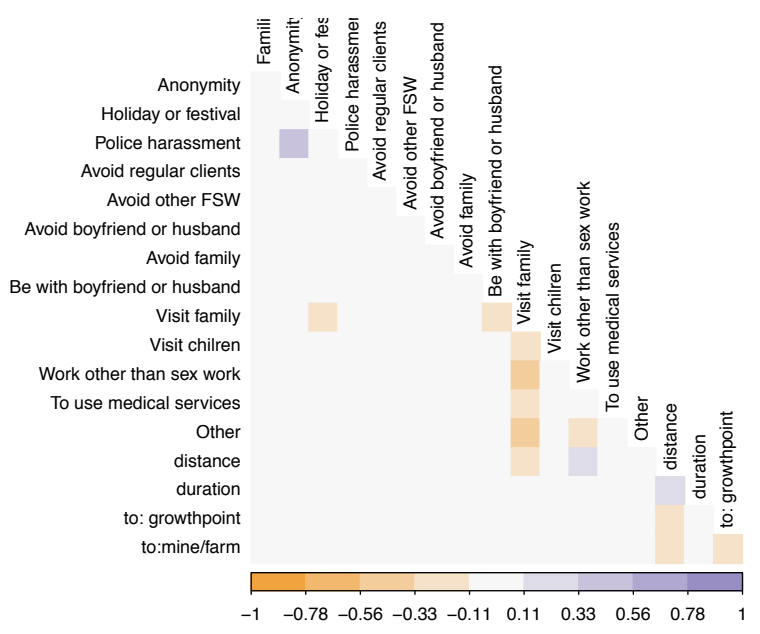

We found little evidence of correlations between the reasons given for moving (see Appendix Figure A2) For moves that included sex work, there was a weak positive correlation between moving for more money and more clients, and weak negative correlation between moving for more money and towards relationships, work other than sex work, or travel with a client. For journeys that did not involve sex work, there was positive correlation between police harassment and anonymity; and negative correlations between visiting family and work other then sex work and 'other'. 


\section{Appendix 3: LCA diagnostics}

We ran a series of diagnositics to evaluate the fit of models of classes around the minimum bootstrap log-likelihood-ratio test (McLachlan, 1987). This test is more robust than tests that

44

\section{Summary}

of the BIC plot, adapted from Garrett \& Zeger (2000). We calculated the difference between the observed and expected frequencies of each binary variable, and the median of the continuous variables. We computed the bivariate residuals comparing the observed and expected relationships between each of the binary variables. We plotted the observed and expected number of visits reported, log of the median distance travelled, and the frequency of the 50 most common configurations of the reasons for travelling.

To compare the most persemoneous model with models with more classes, we used a make asymtotic assumptions (Reynolds \& Templin, 2004). We followed the steps in Tekle, Gudicha \& Vermunt (2016): the most parsimonious model was used to predict values for the manifest variable; both of the models being compared were then fitted to this predicted data; the log-likelihood ratio was computed; this was repeated 500 times to produce a distribution of the log-likelihood ratio under the null condition, and the observed log-likelihood ratio was compared to this distribution, with the $p$-value calculated as the proportion of the distribution higher than the observed value. Finally, we presented the probabilities for each

maniest variable in each class, and considered the substantive usefulness of additional classes. 
Variables in the LCA

\begin{tabular}{lcc}
\hline Variable & Data type & Data transformation / link function \\
\hline More clients & Binary & Logit \\
Clients with more money & Binary & Logit \\
Earn more for being new & Binary & Logit \\
Know FSW there & Binary & Logit \\
Travelled with client & Binary & Logit \\
Anonymity & Binary & Logit \\
Visit family & Binary & Logit \\
Other & Binary & Logit \\
Visited growth point & Binary & Logit \\
Visited mine or farm & Binary & Logit \\
Lives in a town & Binary & Logit \\
Median stay over two weeks & Binary & Logit \\
Travelled internationally & Binary & Logit \\
Median journey time (hours) & $>6$ months & Log \\
Number of visits in 12 months & $>6$ 6months & Poisson \\
\hline
\end{tabular}

\section{References}

Garrett, E.S. \& Zeger, S.L. (2000) Latent class model diagnosis. Biometrics. 56 (4), 1055-1067.

McLachlan, G.J. (1987) On bootstrapping the likelihood ratio test stastistic for the number of components in a normal mixture. Applied statistics. 318-324.

Reynolds, J.H. \& Templin, W.D. (2004) Comparing mixture estimates by parametric bootstrapping likelihood ratios. Journal of Agricultural, Biological, and Environmental Statistics. 9 (1), 57.

Tekle, F.B., Gudicha, D.W. \& Vermunt, J.K. (2016) Power analysis for the bootstrap likelihood ratio test for the number of classes in latent class models. Advances in Data Analysis and Classification. 10 (2), 209-224. 


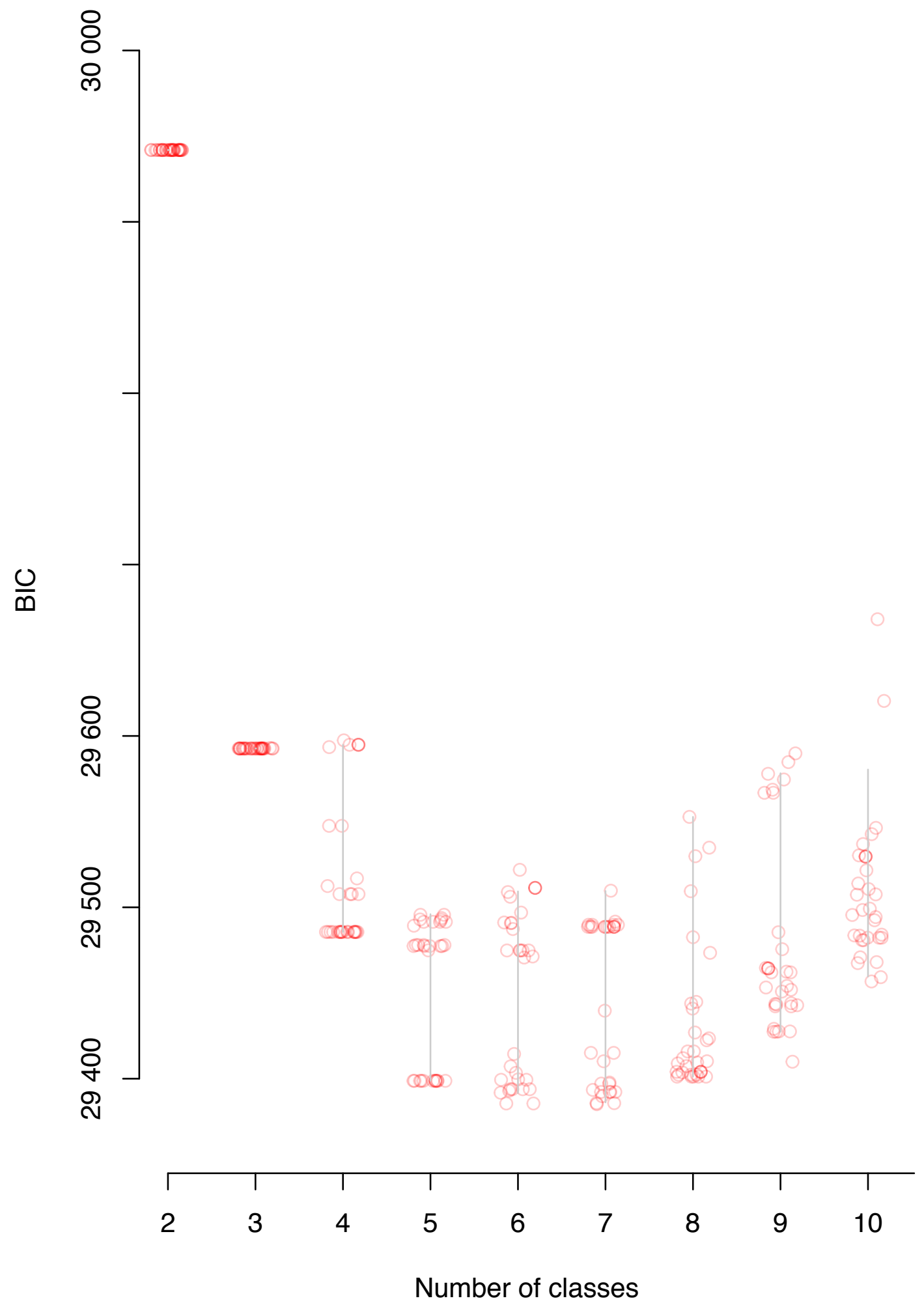

64 The BIQ figure (Figure A3.0) shows that between five and seven classes best fit the data. The grey vertical lines line show the $95 \%$ range of the results of 100 runs. The plot shows that

66 from five classes, or even from four, there is a bi-modal distribution in the BIC centered around 29400 and 29500 . All three of these models produced predicted proportions of the 
binary variables that were very similar to the observed data (see Figures A3.1, A3.2, and A3.3). The five-class model produced some large residuals in the bivariate residuals analysis, especially for the 'travelled with a client' reason for moving, for six and seven classes the residuals were all moderate or small (see Figures A3.4, A3.5, and A3.6). The correlations between observed and expected numbers of visits, log median distance, and combinations of reasons were similar for all three models (see Figures A3.7, A3.8, and A3.8).

74 In the bootstrap-log-likelihood ratio tests, there was evidence for a difference between the four-classs and the five-class models, but not between the five-class and the six-class models (see Figures A3.10 and A3.11).

Contrasting the class sizes predicted from each model (see Figures A3.12, A3.13, and A3.14), and the probability profiles, revealed that there were few substantive differences between the five and six class models. Class 5 in the five-class model decomposed into classes 2 and 6 in the six-class model. Increasing the number of classes from four to five revealed the small class of women who often travelled with clients, who were otherwise classed with the women who worked while moving for other reasons (class 3). 
Observed and predicted proportions

84 Fig. A3.1: Five classes

\begin{tabular}{lccr}
\hline & Observed & Expected & Difference \\
\hline med.over2weeks & 0.5 & 0.5 & 0 \\
international & 0.2 & 0.2 & 0 \\
town & 0.7 & 0.7 & 0 \\
growthpoint & 0.3 & 0.2 & 0 \\
minefarm & 0.3 & 0.2 & 0 \\
r_1 & 0.5 & 0.5 & 0 \\
r_2 & 0.7 & 0.7 & 0 \\
r_3 & 0.3 & 0.3 & 0 \\
r_4 & 0.1 & 0.1 & 0 \\
r_5 & 0.1 & 0.1 & 0 \\
r_7 & 0.1 & 0.1 & 0 \\
r_15 & 0.1 & 0.1 & 0 \\
r_other & 0.2 & 0.2 & 0 \\
visits & 2.0 & 2.0 & 0 \\
med.time & 1.7 & 1.7 & 0 \\
\hline & & & \\
\hline
\end{tabular}

Fig. A3.2: Six classes

\begin{tabular}{lrrr}
\hline & Observed & Expected & Difference \\
\hline med.over2weeks & 0.5 & 0.6 & 0.0 \\
international & 0.2 & 0.2 & 0.0 \\
town & 0.7 & 0.7 & 0.0 \\
growthpoint & 0.3 & 0.3 & 0.0 \\
minefarm & 0.3 & 0.3 & 0.0 \\
r_1 & 0.5 & 0.5 & 0.0 \\
r_2 & 0.7 & 0.6 & 0.0 \\
r_3 & 0.3 & 0.4 & 0.0 \\
r_4 & 0.1 & 0.1 & 0.0 \\
r_5 & 0.1 & 0.1 & 0.0 \\
r_7 & 0.1 & 0.1 & 0.0 \\
r_15 & 0.1 & 0.1 & 0.0 \\
r_other & 0.2 & 0.2 & 0.0 \\
visits & 2.0 & 2.0 & 0.0 \\
med.time & 1.7 & 1.8 & -0.1 \\
\hline
\end{tabular}


Fig. A3.3: Seven classes

\begin{tabular}{lrrr}
\hline & Observed & Expected & Difference \\
\hline med.over2weeks & 0.5 & 0.6 & 0.0 \\
international & 0.2 & 0.2 & 0.0 \\
town & 0.7 & 0.7 & 0.0 \\
growthpoint & 0.3 & 0.3 & 0.0 \\
minefarm & 0.3 & 0.2 & 0.0 \\
r_1 & 0.5 & 0.5 & 0.0 \\
r_2 & 0.7 & 0.7 & 0.0 \\
r_3 & 0.3 & 0.3 & 0.0 \\
r_4 & 0.1 & 0.1 & 0.0 \\
r_5 & 0.1 & 0.1 & 0.0 \\
r_7 & 0.1 & 0.1 & 0.0 \\
r_15 & 0.1 & 0.1 & 0.0 \\
r_other & 0.2 & 0.2 & 0.0 \\
visits & 2.0 & 2.0 & 0.0 \\
med.time & 1.7 & 1.8 & -0.1 \\
\hline
\end{tabular}




\section{Bivariate residuals}

Fig. A3.4: Five classes

\begin{tabular}{|c|c|c|c|c|c|c|c|c|c|c|c|c|}
\hline & international & town & growthpoint & minefarm & r_1 & $\mathrm{r} \_2$ & r_3 & $\mathrm{r}_{-} 4$ & r_5 & $\mathrm{r}_{-} 7$ & r_15 & r_other \\
\hline med.over2weeks & 0.3 & 8.9 & 4.4 & 2.7 & 4.7 & 1.9 & 0.3 & 0.2 & 7.4 & 0.9 & 4.3 & 3.7 \\
\hline international & & 9.6 & 14.6 & 2.5 & 0.9 & 0.3 & 4.7 & 0.2 & 0.4 & 1.2 & 2.6 & 5.2 \\
\hline town & & & 5.8 & 11.6 & 3.1 & 4.7 & 12.8 & 2.1 & 2.2 & 2.5 & 5.8 & 14.0 \\
\hline growthpoint & & & & 7.1 & 6.5 & 4.0 & 7.6 & 4.1 & 8.8 & 6.3 & 9.3 & 17.7 \\
\hline minefarm & & & & & 2.6 & 2.8 & 3.7 & 3.8 & 2.8 & 4.5 & 5.4 & 5.5 \\
\hline $\mathrm{r}_{-} 1$ & & & & & & 0.6 & 2.0 & 0.7 & 0.7 & 6.5 & 3.3 & 3.8 \\
\hline r_2 & & & & & & & 10.6 & 0.9 & 2.1 & 1.1 & 3.1 & 3.5 \\
\hline r_3 & & & & & & & & 3.0 & 4.5 & 1.9 & 2.5 & 3.6 \\
\hline r_4 & & & & & & & & & 0.4 & 0.9 & 2.5 & 5.9 \\
\hline r_5 & & & & & & & & & & 0.9 & 3.7 & 4.6 \\
\hline $\mathrm{r}_{-} 7$ & & & & & & & & & & & 3.2 & 4.2 \\
\hline r_15 & & & & & & & & & & & & 10.8 \\
\hline
\end{tabular}

Fig. A3.5: Six classes

\begin{tabular}{|c|c|c|c|c|c|c|c|c|c|c|c|c|}
\hline & international & town & growthpoint & minefarm & $r_{-} 1$ & $r_{-} 2$ & r_3 & $\mathrm{r} \_4$ & r_5 & $\mathrm{r}_{-} 7$ & r_15 & r_other \\
\hline med.over2weeks & 6.7 & 4.7 & 8.7 & 6.2 & 7.3 & 9.0 & 5.6 & 6.2 & 8.8 & 7.5 & 19.5 & 5.9 \\
\hline international & & 1.3 & 8.3 & 1.0 & 1.2 & 1.5 & 3.5 & 0.2 & 0.9 & 6.2 & 4.6 & 0.6 \\
\hline town & & & 11.9 & 1.4 & 1.4 & 1.1 & 1.6 & 0.3 & 1.1 & 4.6 & 2.8 & 1.8 \\
\hline growthpoint & & & & 4.1 & 3.4 & 5.9 & 3.8 & 3.0 & 6.6 & 5.9 & 4.9 & 9.2 \\
\hline minefarm & & & & & 1.4 & 3.7 & 7.3 & 1.3 & 2.1 & 3.6 & 1.3 & 4.4 \\
\hline $\mathrm{r}_{-} 1$ & & & & & & 6.4 & 4.7 & 0.2 & 0.2 & 2.9 & 1.5 & 0.8 \\
\hline$r_{-} 2$ & & & & & & & 4.2 & 1.2 & 2.1 & 4.2 & 3.6 & 2.1 \\
\hline r_3 & & & & & & & & 4.3 & 1.0 & 4.4 & 1.8 & 1.4 \\
\hline r_4 & & & & & & & & & 0.9 & 3.2 & 0.8 & 1.7 \\
\hline$r_{-} 5$ & & & & & & & & & & 4.3 & 0.9 & 7.1 \\
\hline $\mathrm{r}_{-} 7$ & & & & & & & & & & & 7.6 & 3.2 \\
\hline r_15 & & & & & & & & & & & & 1.5 \\
\hline
\end{tabular}


Fig. A3.6: Seven classes

\begin{tabular}{|c|c|c|c|c|c|c|c|c|c|c|c|c|}
\hline & international & town & growthpoint & minefarm & r_1 & $\mathrm{r} \_2$ & r_3 & r_4 & r_5 & r_7 & r_15 & r_other \\
\hline med.over2weeks & 2.7 & 8.8 & 8.0 & 1.6 & 6.5 & 1.9 & 2.1 & 4.7 & 9.0 & 1.2 & 3.5 & 1.6 \\
\hline international & & 4.3 & 9.9 & 0.7 & 2.5 & 4.9 & 0.1 & 3.5 & 2.2 & 0.3 & 2.8 & 0.2 \\
\hline town & & & 3.8 & 6.6 & 2.6 & 0.6 & 7.2 & 1.9 & 0.8 & 1.2 & 8.3 & 5.8 \\
\hline growthpoint & & & & 1.6 & 4.2 & 0.4 & 0.2 & 0.2 & 1.3 & 2.3 & 2.8 & 1.1 \\
\hline minefarm & & & & & 3.3 & 2.2 & 1.2 & 2.6 & 2.1 & 1.0 & 11.4 & 0.7 \\
\hline r_1 & & & & & & 7.4 & 2.8 & 6.4 & 2.6 & 5.5 & 7.1 & 10.9 \\
\hline r_2 & & & & & & & 27.2 & 1.2 & 1.7 & 0.4 & 4.0 & 3.2 \\
\hline r_3 & & & & & & & & 2.9 & 1.6 & 8.5 & 2.4 & 3.9 \\
\hline r_ 4 & & & & & & & & & 0.8 & 1.0 & 3.4 & 1.3 \\
\hline r_5 & & & & & & & & & & 0.9 & 3.5 & 0.8 \\
\hline$r_{-} 7$ & & & & & & & & & & & 6.2 & 0.5 \\
\hline r_15 & & & & & & & & & & & & 8.6 \\
\hline
\end{tabular}


Observed vs expected plots (visits, log median distance, cases)

Fig. A3.7: Five classes
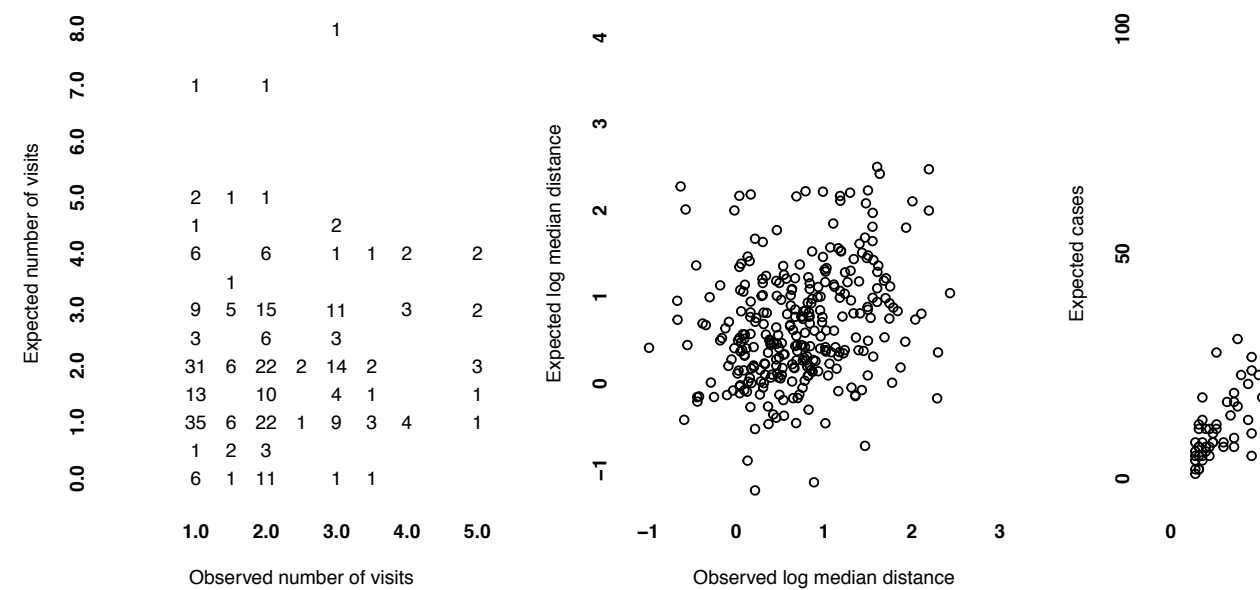

0

100

Fig. A3.8: Six classes

96
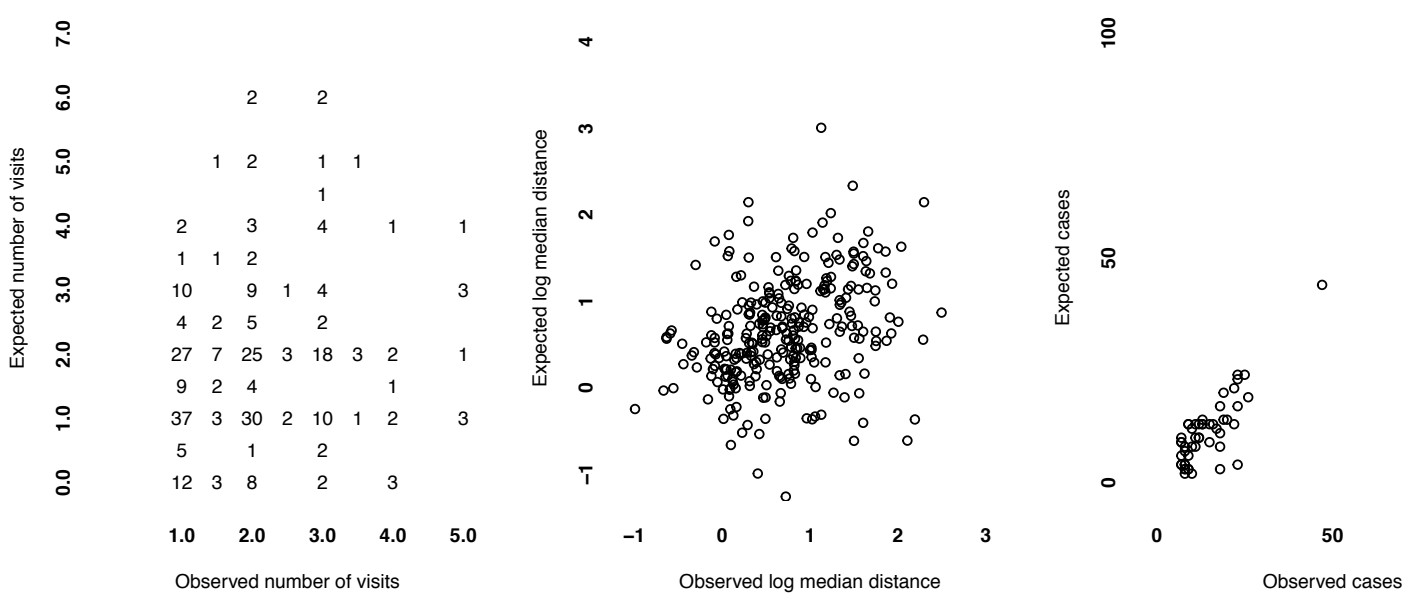

100 
Fig. A3.9: Seven classes

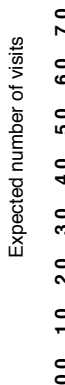

100

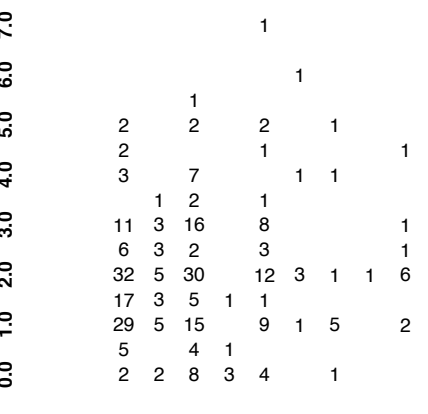

$\begin{array}{lllll}1.0 & 2.0 & 3.0 & 4.0 & 5.0\end{array}$

Observed number of visits
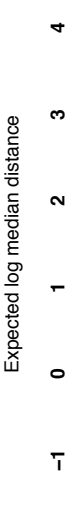

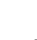

$\stackrel{\circ}{\circ}$

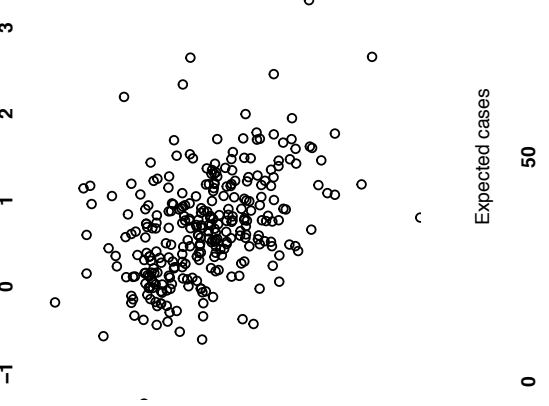

$\begin{array}{lll}0 & 1 & 2\end{array}$

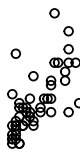

50

Observed cases 


\section{Bootstrap log-likelihood ratio tests}

Fig. A3.10: 4-class and 5-class models

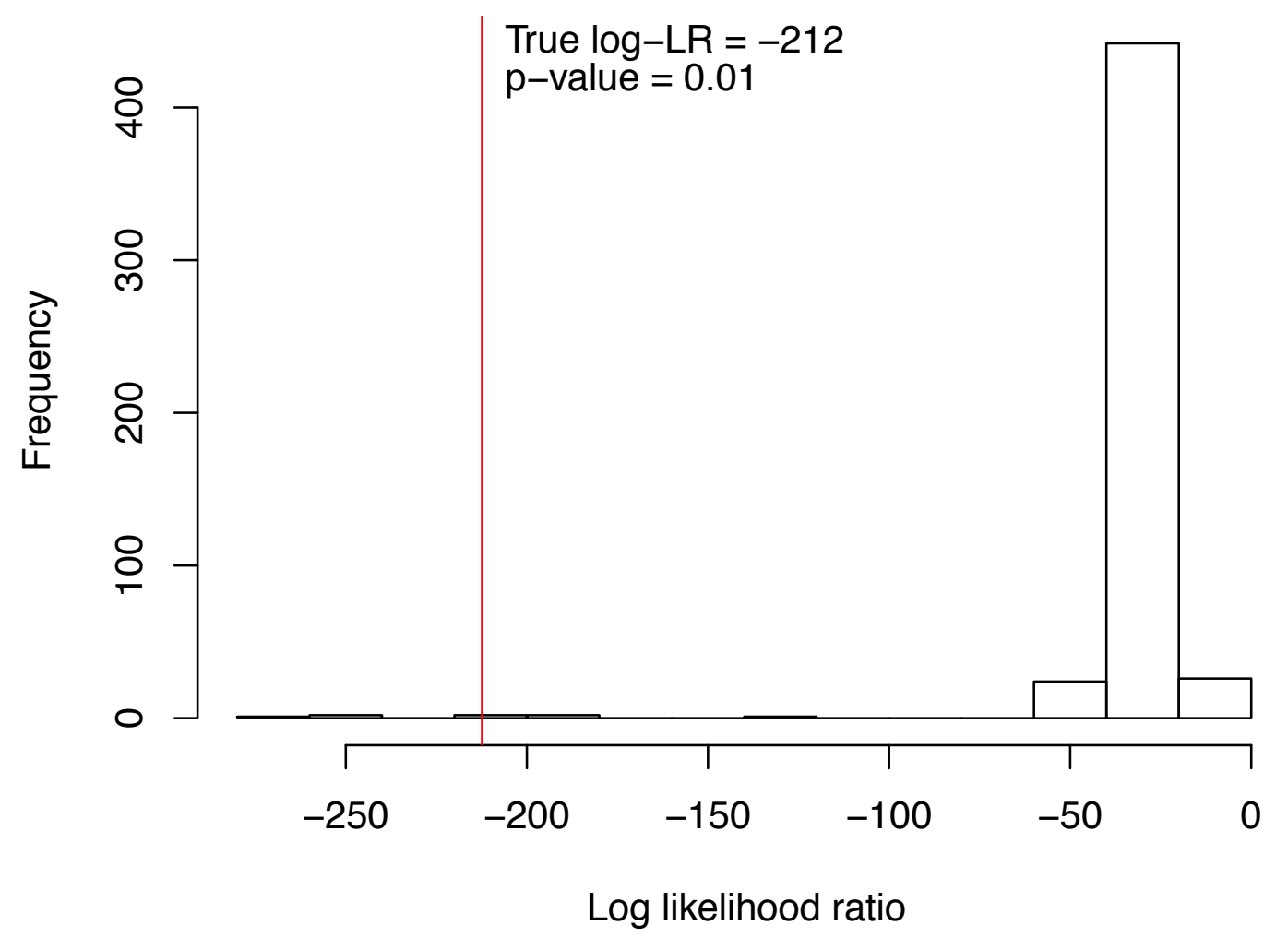

Fig. A3.11: 5-class and 6-class models

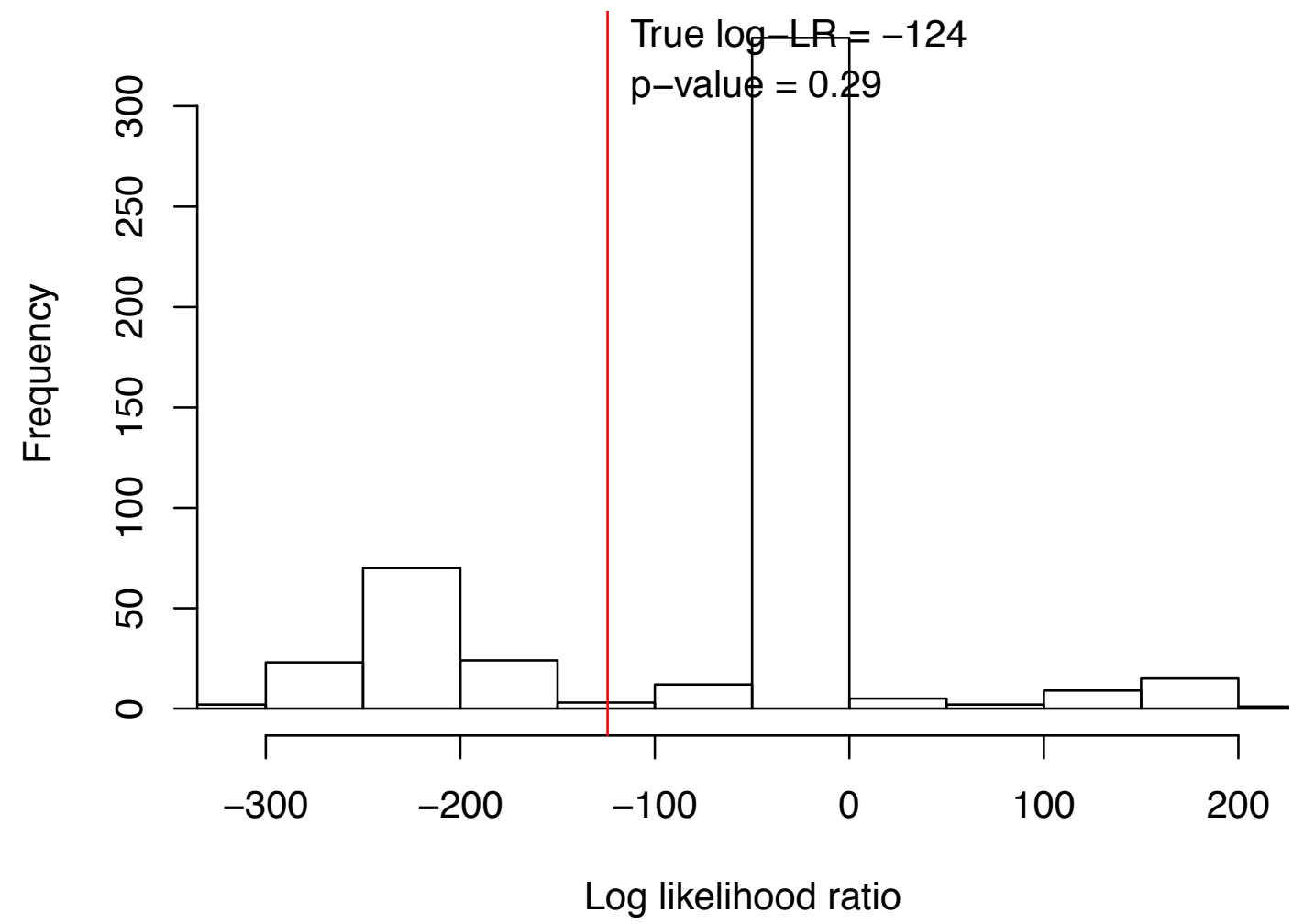


Classes and item probabilities

Fig. A3.12: Four-class

108

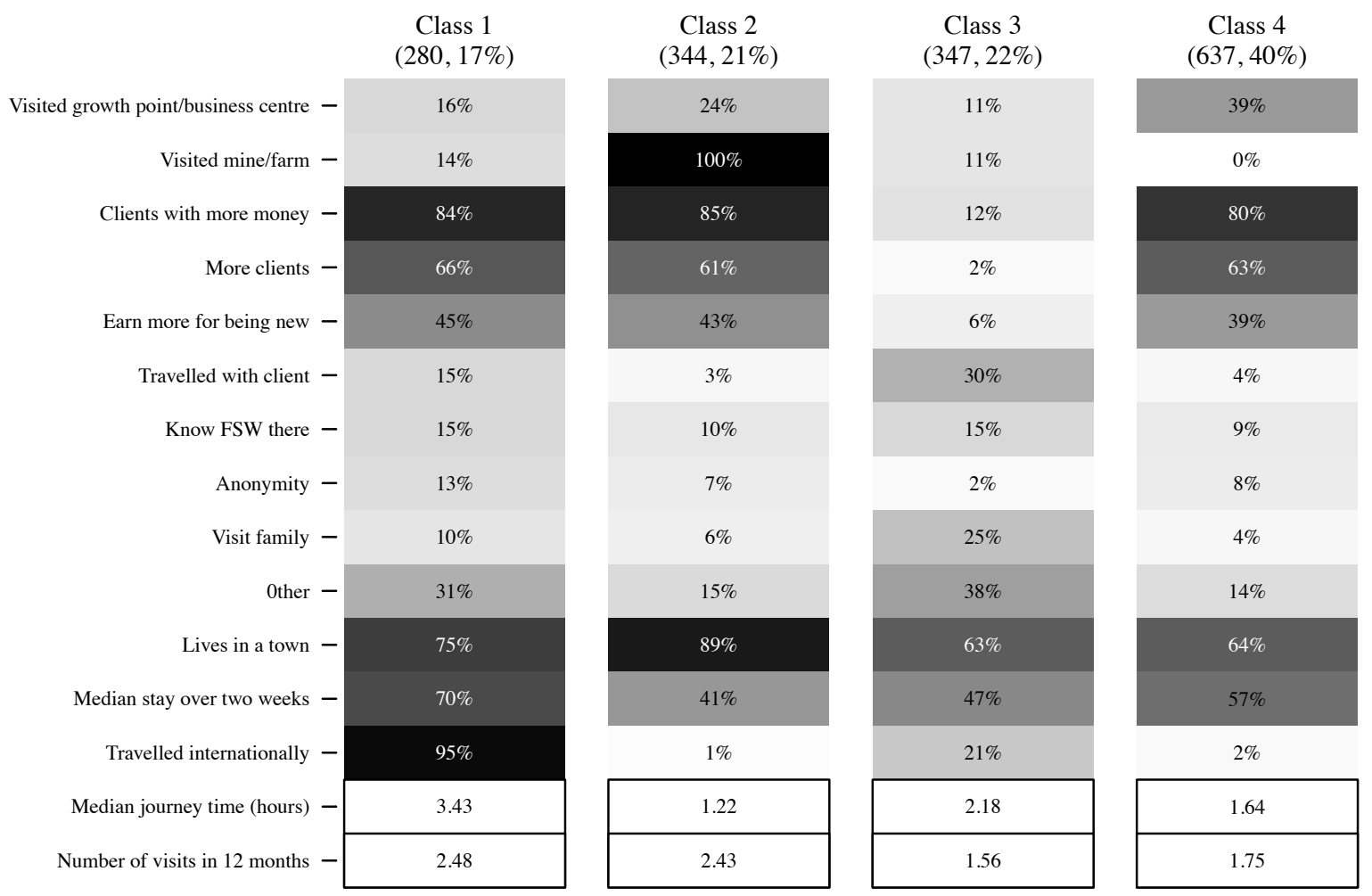


Fig. A3.12: Five-class - repeated from Figure 2 in manuscript

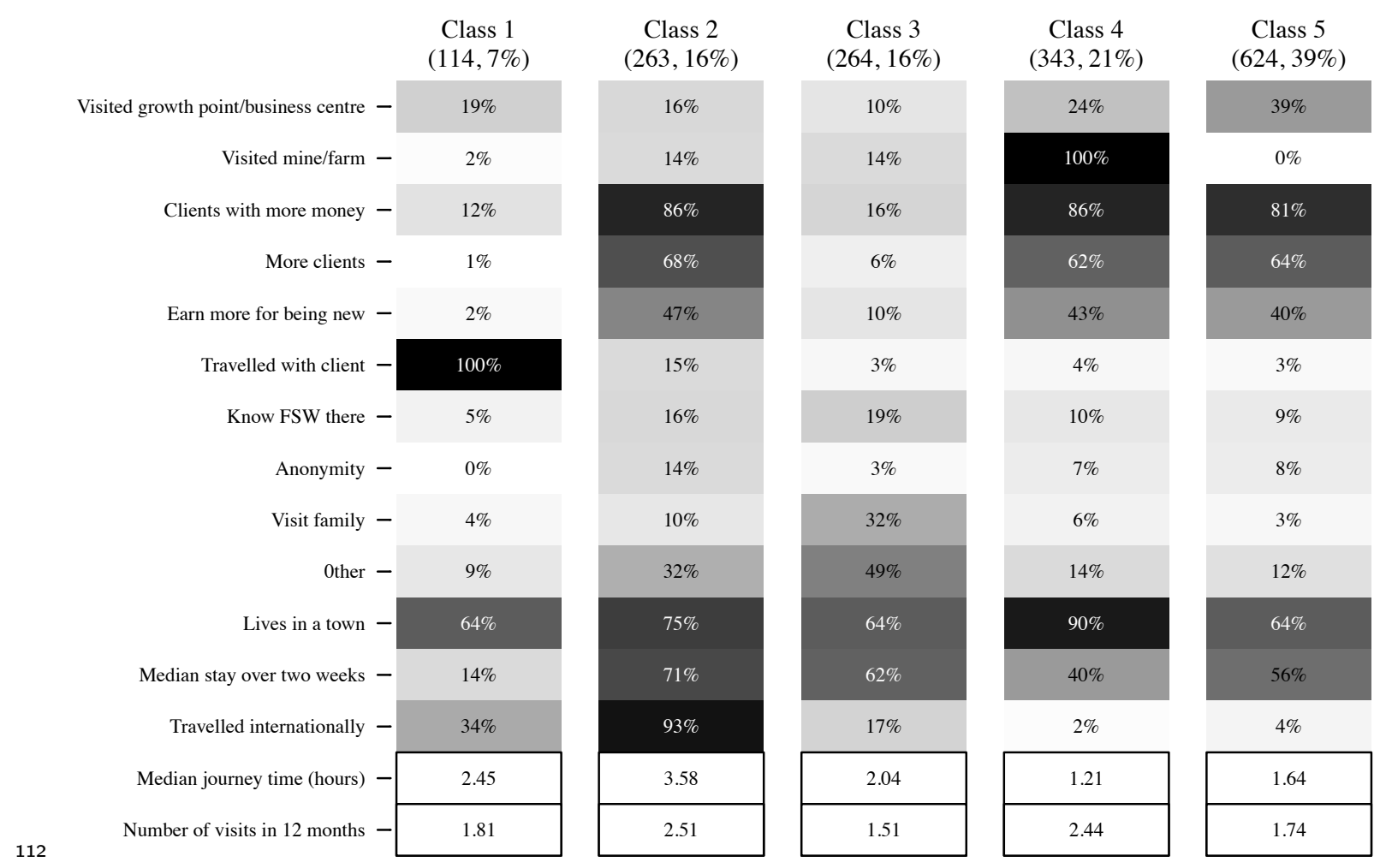

Fig. A3.13: Six-class

114

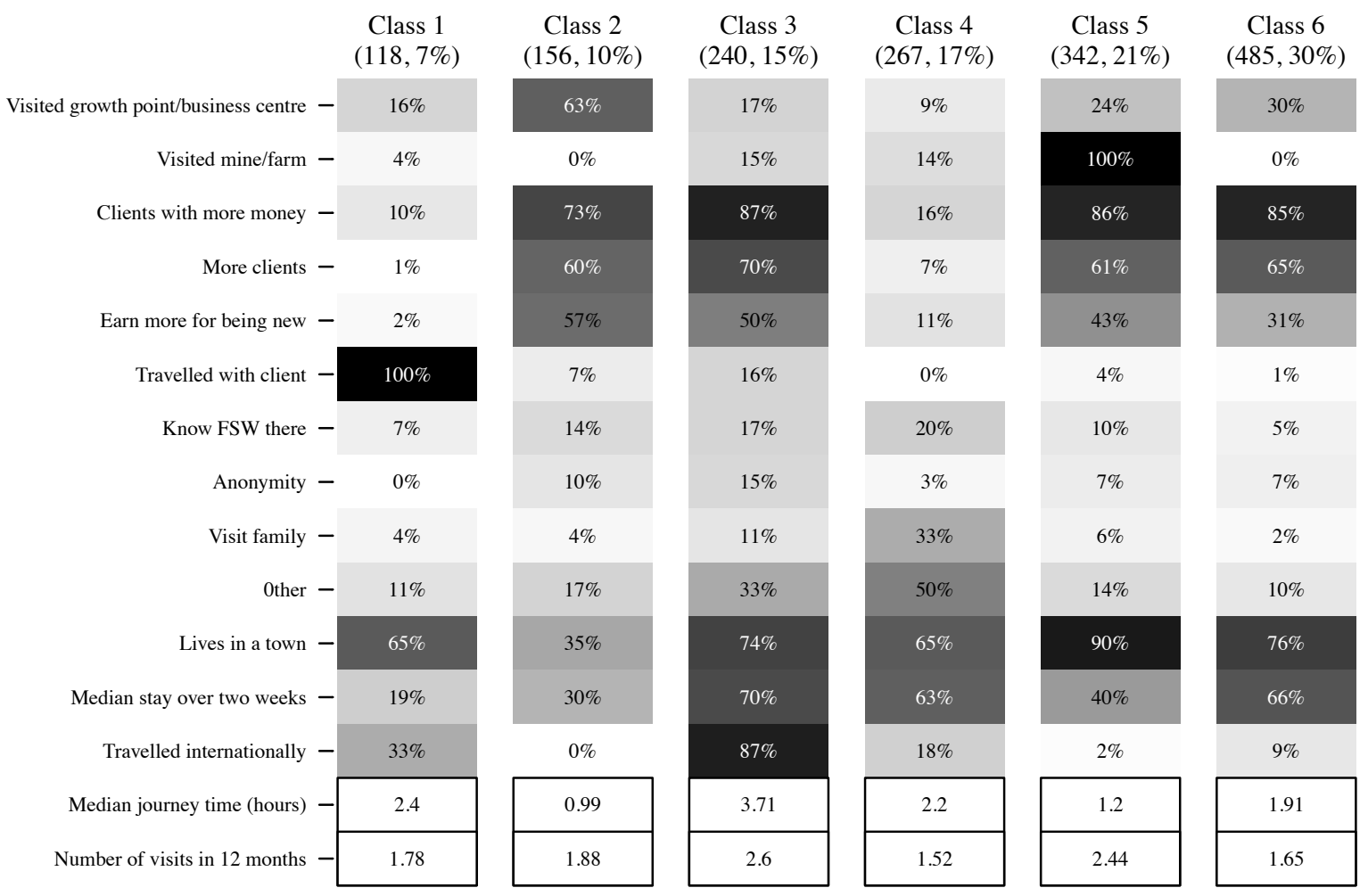




\begin{tabular}{|c|c|c|c|c|c|c|c|}
\hline & $\begin{array}{c}\text { Class } 1 \\
(68,4 \%)\end{array}$ & $\begin{array}{c}\text { Class } 2 \\
(119,7 \%)\end{array}$ & $\begin{array}{c}\text { Class } 3 \\
(149,9 \%)\end{array}$ & $\begin{array}{c}\text { Class } 4 \\
(194,12 \%)\end{array}$ & $\begin{array}{c}\text { Class } 5 \\
(245,15 \%)\end{array}$ & $\begin{array}{c}\text { Class } 6 \\
(273,17 \%)\end{array}$ & $\begin{array}{c}\text { Class } 7 \\
(560,35 \%)\end{array}$ \\
\hline Visited growth point/business centre & $79 \%$ & $20 \%$ & $63 \%$ & $4 \%$ & $9 \%$ & $10 \%$ & $29 \%$ \\
\hline Visited mine/farm - & $45 \%$ & $4 \%$ & $35 \%$ & $8 \%$ & $14 \%$ & $100 \%$ & $0 \%$ \\
\hline Clients with more money & $93 \%$ & $14 \%$ & $82 \%$ & $82 \%$ & $9 \%$ & $86 \%$ & $81 \%$ \\
\hline More clients - & $100 \%$ & $2 \%$ & $65 \%$ & $65 \%$ & $5 \%$ & $56 \%$ & $59 \%$ \\
\hline Earn more for being new & $79 \%$ & $2 \%$ & $42 \%$ & $48 \%$ & $7 \%$ & $38 \%$ & $36 \%$ \\
\hline Travelled with client - & $15 \%$ & $100 \%$ & $9 \%$ & $15 \%$ & $2 \%$ & $2 \%$ & $0 \%$ \\
\hline Know FSW there - & $35 \%$ & $5 \%$ & $15 \%$ & $14 \%$ & $21 \%$ & $8 \%$ & $5 \%$ \\
\hline Anonymity - & $14 \%$ & $0 \%$ & $8 \%$ & $17 \%$ & $3 \%$ & $7 \%$ & $7 \%$ \\
\hline Visit family & $11 \%$ & $4 \%$ & $9 \%$ & $11 \%$ & $36 \%$ & $5 \%$ & $1 \%$ \\
\hline Other - & $32 \%$ & $10 \%$ & $31 \%$ & $34 \%$ & $53 \%$ & $9 \%$ & $8 \%$ \\
\hline Lives in a town - & $43 \%$ & $63 \%$ & $97 \%$ & $70 \%$ & $61 \%$ & $90 \%$ & $63 \%$ \\
\hline Median stay over two weeks & $33 \%$ & $15 \%$ & $73 \%$ & $72 \%$ & $61 \%$ & $36 \%$ & $56 \%$ \\
\hline Travelled internationally - & $9 \%$ & $32 \%$ & $28 \%$ & $95 \%$ & $13 \%$ & $0 \%$ & $7 \%$ \\
\hline Median journey time (hours) & 1.09 & 2.3 & 2.26 & 4.26 & 2.21 & 1.1 & 1.56 \\
\hline Number of visits in 12 months & 3.11 & 1.82 & 2.92 & 2.29 & 1.5 & 2.16 & 1.5 \\
\hline
\end{tabular}




\section{Appendix 4: mobility in Zimbabwe DHS}

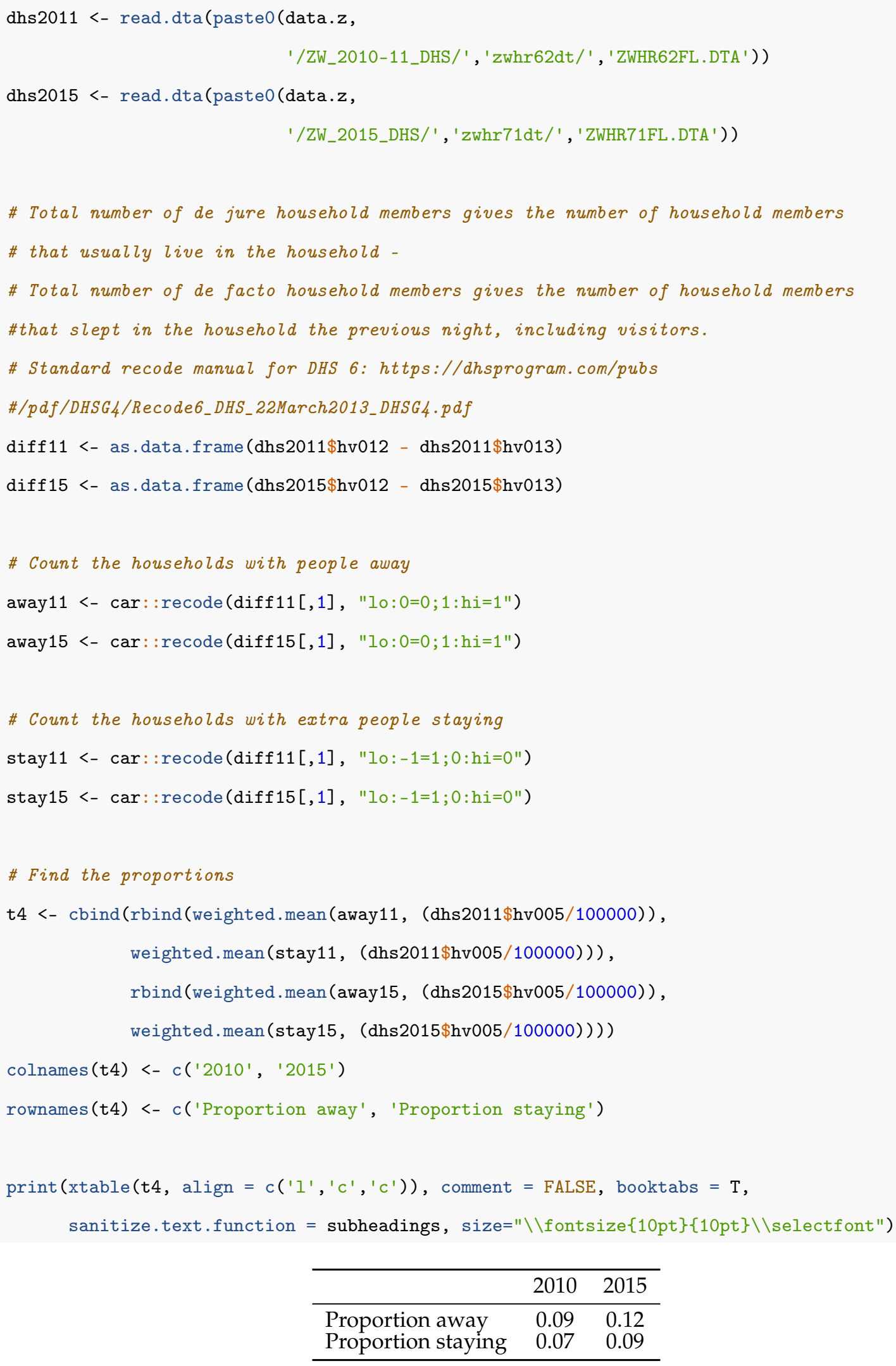

\begin{tabular}{lcc}
\hline & 2010 & 2015 \\
\hline Proportion away & 0.09 & 0.12 \\
Proportion staying & 0.07 & 0.09 \\
\hline
\end{tabular}




\section{Appendix 5: geocoding code}

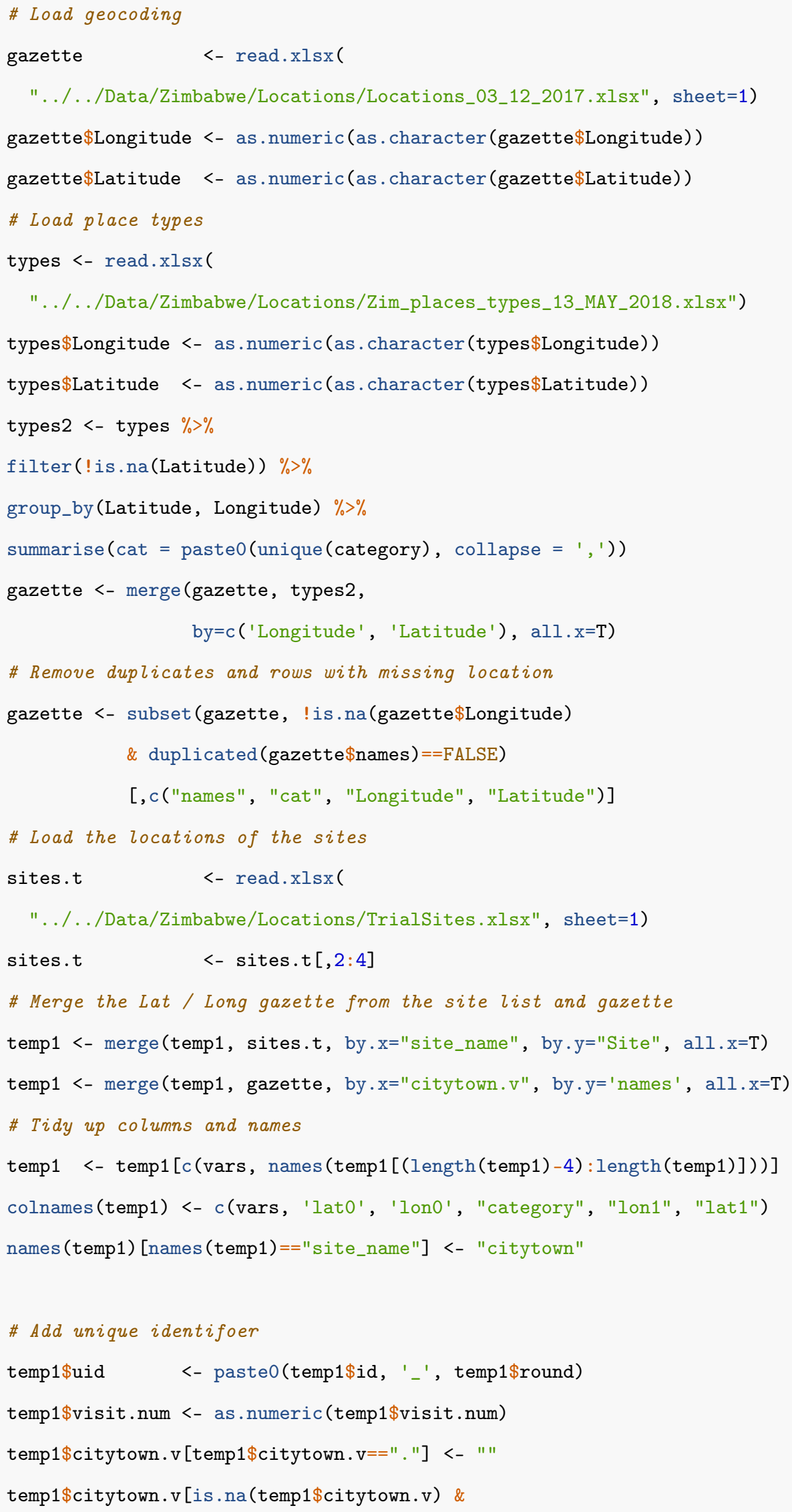




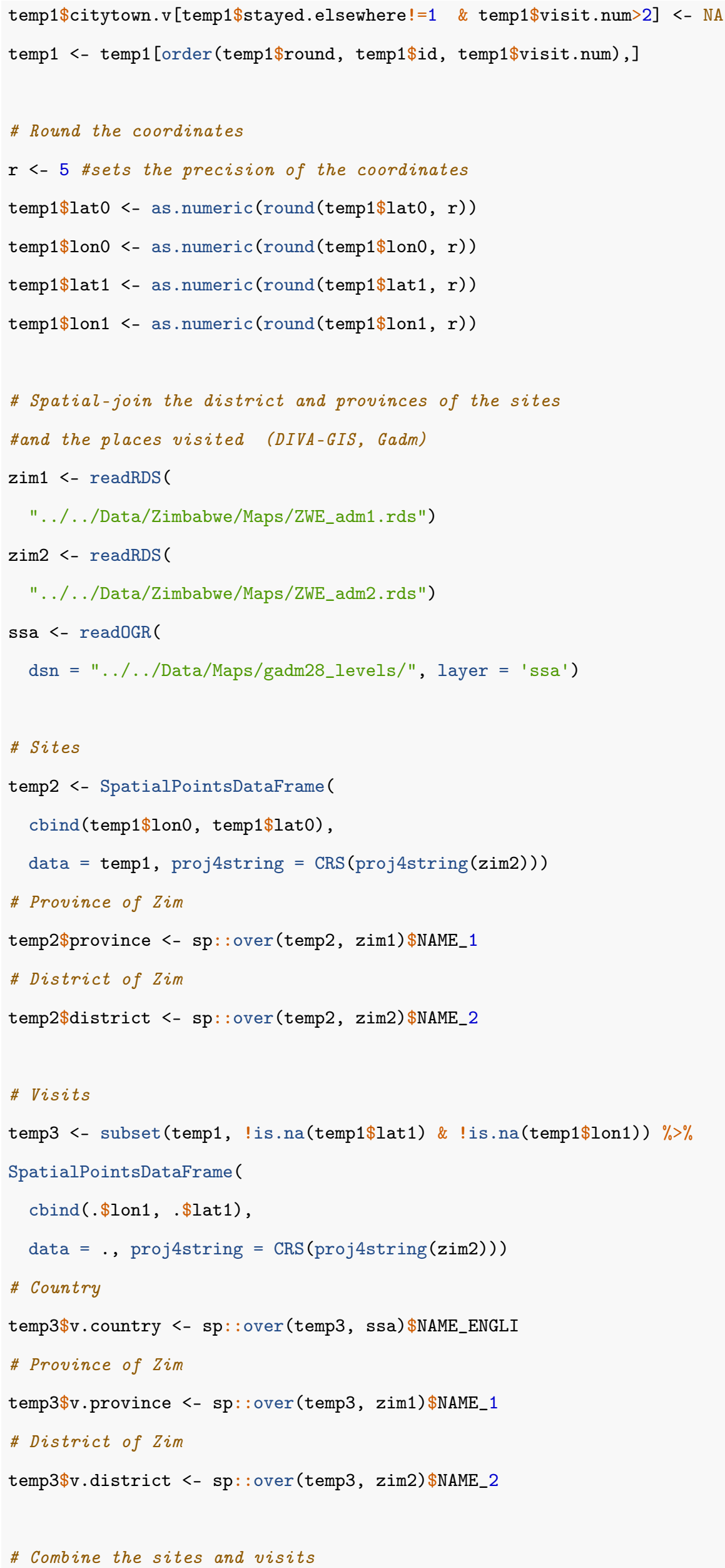




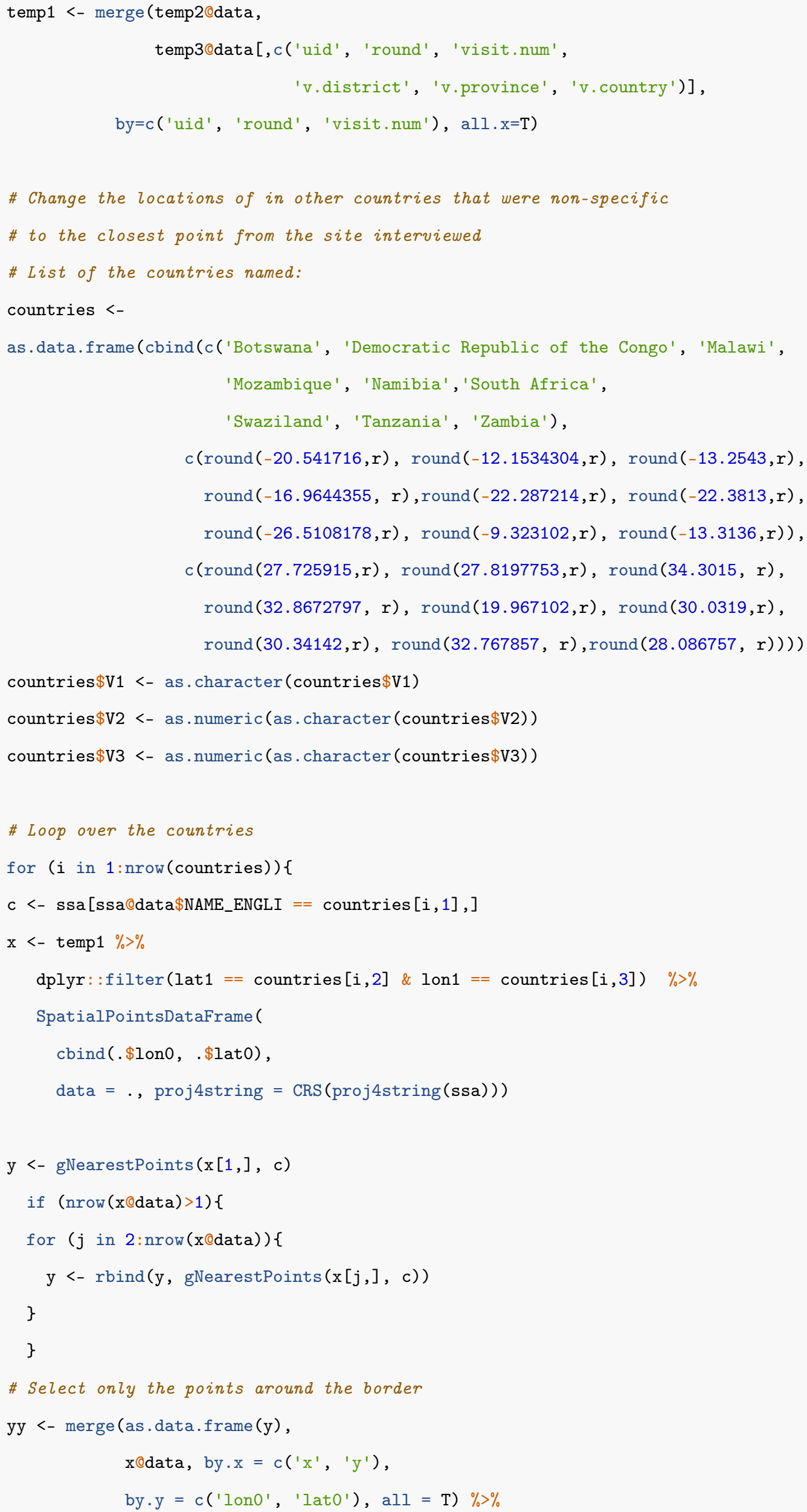




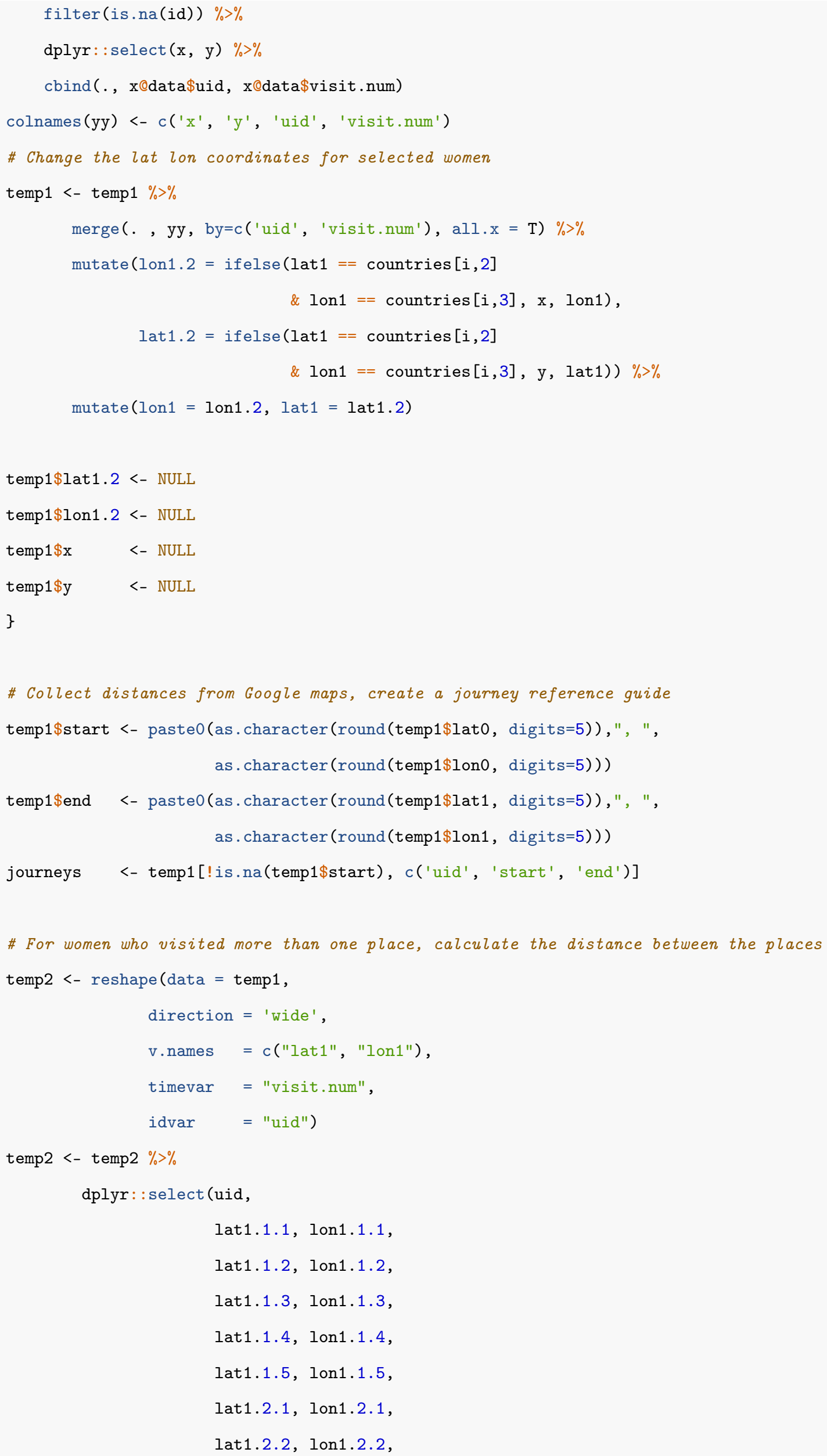


lat1.2.3, lon1.2.3,

lat1.2.4, lon1.2.4,

lat1.2.5, lon1.2.5)

$\mathrm{m}<-\operatorname{matrix}(\mathrm{c}(1,2,3,4,2,3,4,5), \mathrm{ncol}=2)$

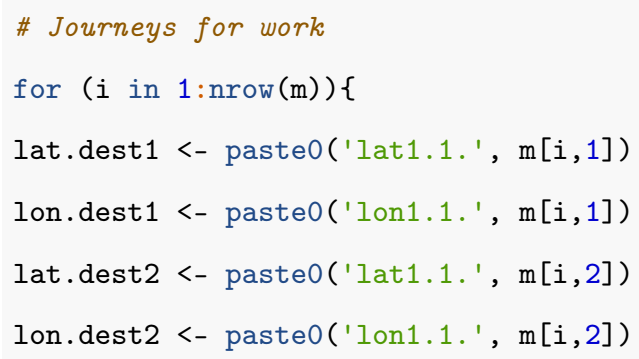




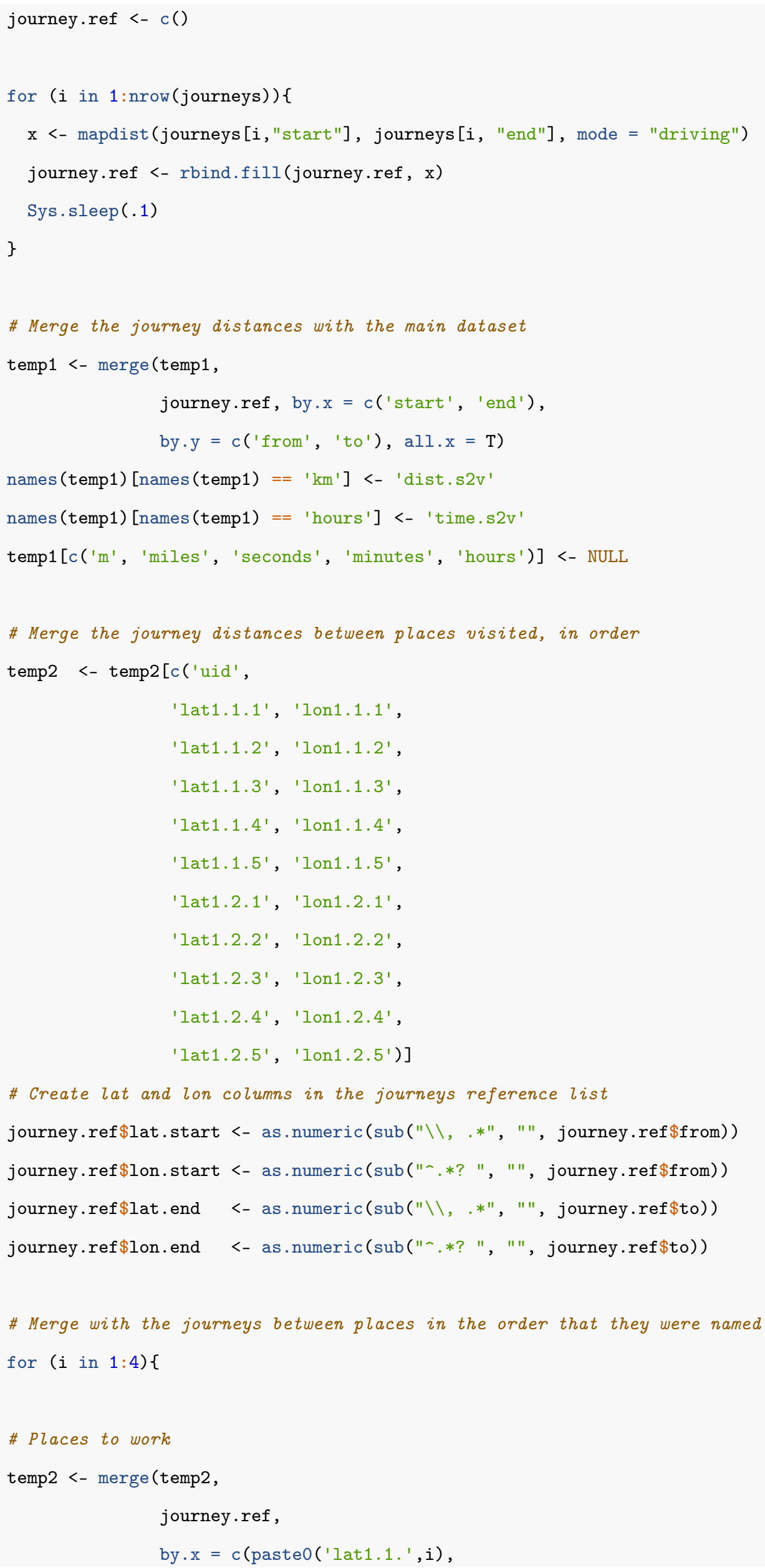




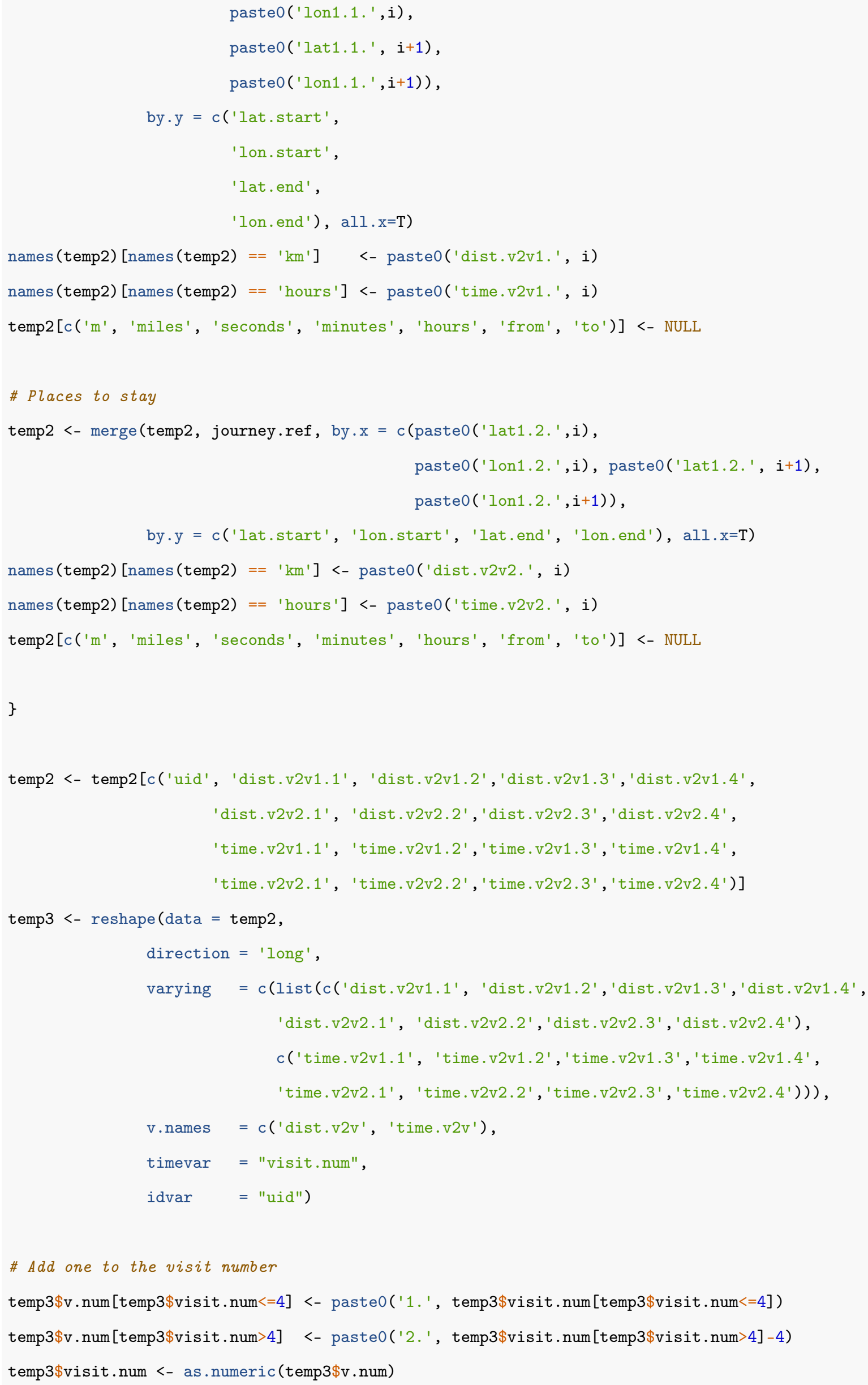




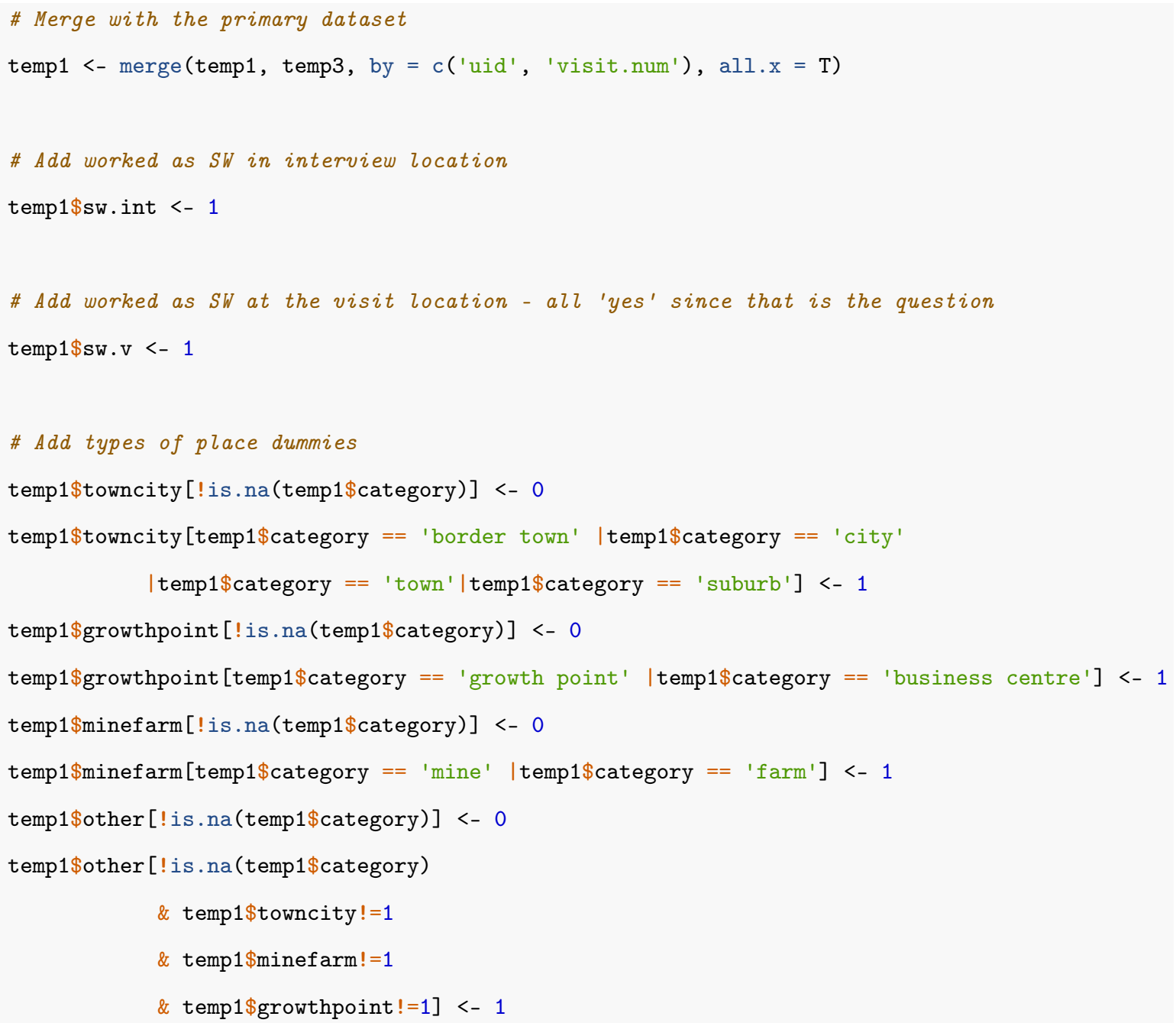

